\title{
Engineering Lactococcus lactis as a multi-stress tolerant biosynthetic chassis by deleting the prophage-related fragment
}

\author{
Wanjin Qiao ${ }^{1,2}$, Yu Qiao ${ }^{1}$, Fulu Liu' ${ }^{1}$ Yating Zhang ${ }^{1}$, Ran Li ${ }^{2}$, Zhenzhou Wu ${ }^{3}$, Haijin Xu ${ }^{1 *}$, Per Erik Joakim Saris ${ }^{2}$ \\ and Mingqiang Qiao ${ }^{1 *}$ (D)
}

\begin{abstract}
Background: In bioengineering, growth of microorganisms is limited because of environmental and industrial stresses during fermentation. This study aimed to construct a nisin-producing chassis Lactococcus lactis strain with genome-streamlined, low metabolic burden, and multi-stress tolerance characteristics.

Results: The Cre-loxP recombination system was applied to reduce the genome and obtain the target chassis strain. A prophage-related fragment (PRF; 19,739 bp) in the L. lactis N8 genome was deleted, and the mutant strain L. lactis N8-1 was chosen for multi-stress tolerance studies. Nisin immunity of L. lactis N8-1 was increased to 6500 IU/ $\mathrm{mL}$, which was $44.44 \%$ higher than that of the wild-type L. lactis N8 $(4500 \mathrm{IU} / \mathrm{mL})$. The survival rates of L. lactis N8-1 treated with lysozyme for $2 \mathrm{~h}$ and lactic acid for $1 \mathrm{~h}$ were 1000- and 10,000-fold higher than that of the wild-type strain, respectively. At $39{ }^{\circ} \mathrm{C}$, the L. lactis N8-1 could still maintain its growth, whereas the growth of the wild-type strain dramatically dropped. Scanning electron microscopy showed that the cell wall integrity of L. lactis N8-1 was well maintained after lysozyme treatment. Tandem mass tags labeled quantitative proteomics revealed that 33 and 9 proteins were significantly upregulated and downregulated, respectively, in L. lactis N8-1. These differential proteins were involved in carbohydrate and energy transport/metabolism, biosynthesis of cell wall and cell surface proteins.
\end{abstract}

Conclusions: PRF deletion was proven to be an efficient strategy to achieve multi-stress tolerance and nisin immunity in L. lactis, thereby providing a new perspective for industrially obtaining engineered strains with multi-stress tolerance and expanding the application of lactic acid bacteria in biotechnology and synthetic biology. Besides, the importance of PRF, which can confer vital phenotypes to bacteria, was established.

Keywords: Lactococcus lactis, Prophage-related fragment, Genome editing, Multi-stress tolerance, Nisin immunity, Nisin yield, TMT quantitative proteomics

\section{Background}

The microbial cell factory, which mainly involves microorganisms to produce organic acids, chemicals, and antimicrobial peptides, is used for various purposes in

\footnotetext{
*Correspondence: nkxuhaijin@163.com; qiaomq@nankai.edu.cn

1 Key Laboratory of Molecular Microbiology and Technology, Ministry

of Education, College of Life Sciences, Nankai University, No.94 Weijin Road, Nankai District, Tianjin 300071, China

Full list of author information is available at the end of the article
}

industrial biotechnology [1]. Lactic acid bacteria (LAB) are commonly used as microbial cell factories [2] and Lactococcus lactis (L. lactis) is particularly employed to produce the food additive (E234) nisin. However, microorganisms often encounter environmental stress, including oxidative, acid, and heat stresses [3]. Moreover, nisin producers have to tolerate the stress caused by the antibacterial nisin. To date, only limited studies have reported on the construction of microbial chassis L. lactis strains to enhance multi-stress tolerance, reduce

(C) The Author(s) 2020. This article is licensed under a Creative Commons Attribution 4.0 International License, which permits use, sharing, adaptation, distribution and reproduction in any medium or format, as long as you give appropriate credit to the original author(s) and the source, provide a link to the Creative Commons licence, and indicate if changes were made. The images or other third party material in this article are included in the article's Creative Commons licence, unless indicated otherwise in a credit line to the material. If material is not included in the article's Creative Commons licence and your intended use is not permitted by statutory regulation or exceeds the permitted use, you will need to obtain permission directly from the copyright holder. To view a copy of this licence, visit http://creativeco mmons.org/licenses/by/4.0/. The Creative Commons Public Domain Dedication waiver (http://creativecommons.org/publicdomain/ zero/1.0/) applies to the data made available in this article, unless otherwise stated in a credit line to the data. 
metabolic burden, and boost desirable product fermentation. Therefore, there is an urgent need to engineer $\mathrm{LAB}$ in order to adapt to extreme environmental pressures and accomplish normal growth and high production of valuable compounds [4].

In recent years, researchers have adapted strains with stress tolerance through different strategies, e.g., random mutagenesis, global transcription machinery engineering (gTME), global regulator overexpression and genome editing. Random mutagenesis has been extensively used to improve the acid tolerance of microbial cells. The global regulator Sigma D factor (RpoD) of Escherichia coli (E. coli) had been tailored by mutagenesis to achieve enhanced acid resistance, and the best mutant exhibited much higher growth rate than the control $\left(0.22 \mathrm{~h}^{-1}\right.$ vs $0.15 \mathrm{~h}^{-1}$ ) at $\mathrm{pH} 3.17$ [5]. The ethanol tolerance of Saccharomyces cerevisiae (S. cerevisiae) had been increased after gTME by reprogramming gene transcription [6]. The survival rate of $E$. coli had been noted to increase by 10 - to 100 -fold at $\mathrm{pH} 2.5$ by overexpressing the global regulator $\mathrm{H}-\mathrm{NS}$ [7]. Li et al. overexpressed sHSP20 in E. coli BL21 cells and increased its survival period at $50{ }^{\circ} \mathrm{C}$ by almost $2 \mathrm{~h}$ [8], while deletion of $A D Y 2$ improved the growth of $S$. cerevisiae under acetic acid, ethanol, and hydrogen peroxide stresses [9].

The two major methods to improve stress tolerance of $\mathrm{LAB}$ are heterologous expression [10] and endogenous overexpression [11]. In addition, genome shuffling has also been applied to improve acid tolerance and volumetric productivity of an industrial strain Lactobacillus rhamnosus ATCC 11443 [12]. Besides, small RNA like sRNA-s015 [13] has also been reported to be an important factor that affects stress tolerance. Recently, the resistance or survival rates of $L$. lactis have been improved by exposing the bacterial cells to transglutaminase [14], bacteriocin Lcn972 [15], and Tween 80 [16] during growth.

In general, deletion of non-essential genome fragments, such as prophages and transposons, could confer some advantages on bacterial strains [17], including enhanced growth, increased biomass, and higher level of proteins synthesis [18]. Besides, prophages can usually synthesize proteins like prophage lysin that affect the host cell wall/membrane [19], and cell wall/membrane is essential for maintaining cellular integrity and resisting environmental stress [20]. For instance, the structure of the cell wall/membrane of nisin-producing $L$. lactis can also affect its tolerance to nisin [21]. Therefore, deletion of prophage-related fragments (PRFs) might affect multistress tolerance, nisin immunity, and nisin production of LAB. However, studies on the multi-stress tolerance of LAB are limited. For example, in a previous study, a putatively prophage-deleted derivative of $L$. lactis UC509 was constructed and the type and integrity of the prophage were investigated [22]. Likewise, L. lactis IL1403 derivatives were constructed and all the PRFs were deleted; however, the functions of these prophages in the strain were not explored [23]. Furthermore, a chassis derivative of L. lactis NZ9000 was generated, which exhibited superior growth phenotype and higher heterologous protein synthesis, but did not present multi-stress tolerance [4]. It must be noted that the above-mentioned studies did not include nisin-producing strains. The level of nisin production by a nisin producer could be regulated by the producer's immunity to nisin [24]. Thus, to ensure growth and efficient production, L. lactis N8 must have the ability to resist nisin inhibition. In general, the nisin immunity of a producer is determined by different mechanisms, namely, structure of cell wall/membrane [21], local $\mathrm{pH}$ at the outer surface of the cytoplasmic membrane [25], nisin-digesting enzyme [26], and nisin immunity genes [27].

Bacterial tolerance is a complex regulatory mechanism. Before the advancement of proteomics technology, there was no systematic research method to understand bacterial tolerance at the protein level. Two-dimensional gel electrophoresis (2-DE) is a traditional method to identify "upregulated" and "downregulated" proteins [28]. However, 2-DE has limitations such as low resolution and bias against membrane proteins. In recent years, mass spectrometry (MS) technology has been widely used for the analysis of complex protein mixtures, and MS-based proteins quantitative analysis has replaced 2-DE proteomics. When compared with transcriptomics gene expression studies, proteomics can directly measure the level of gene products in a specific state and can further characterize protein activity, interaction, and subcellular distribution [29]. Proteomics has been successfully applied in various fields, such as determination of protein composition of organelles, elucidation of protein-protein interactions, and large-scale mapping of protein phosphorylation in response to stimuli [30]. Tandem mass tags (TMT)labeled MS for protein synthesis analysis has been widely used to study the tolerance mechanism of microorganisms [29].

In the present study, TMT-labeled proteomics technology was applied to trace the changes in the protein synthesis of mutant strains. Functional analysis of differentially synthetized proteins was performed, and the protein response mechanism was elucidated based on enrichment results. The mechanism of multi-stress tolerance of the strain was also elaborated at the proteome level, and the results obtained can provide a basis for subsequent research in related fields. A PRF was deleted from L. lactis $\mathrm{N} 8$ genome using the Cre-loxP recombination system [31], and the mutant L. lactis N8-1 
outperformed the wild-type strain in several physiological traits assessed, including better stress tolerance and higher nisin yield in acidic fermentation. TMT quantitative proteomics showed that the upregulated proteins were mainly enriched in sugar metabolism and biosynthesis of cell wall and cell surface proteins. The findings of this study provide new strategies for developing industrial strains with increased multi-stress tolerance and a novel perspective for the acquisition of highly robust strains.

\section{Results}

\section{Design and construction of L. lactis N8-1}

To construct the mutant strains, PHAST (PHAge Search Tool) was used for PRF prediction (http://phast.wishartlab.com/) [32]. The genome of $L$. lactis N8 contains seven PRFs (about $0.231 \mathrm{Mb}$ ), constituting $8.98 \%$ of the L. lactis N8 genome (about $2.57 \mathrm{Mb}$ ) (Fig. 1a). By using the Cre-loxP recombination system, one PRF was deleted. The location of the deleted PRF in L. lactis N8 is shown in Fig. 1b, and the genetic components of the deleted PRF are presented in Fig. 1c. The deleted PRF was $19.7 \mathrm{~kb}$ and contained 22 open reading frames. Among these genes, 14 have been characterized and one encodes phage integrase. A detailed description of the genes is provided in Additional file 1: Table S1. The deletion result was verified by PCR with confirmation primers and genome resequencing (Fig. 1d, e).

\section{Mutant strain showed increased nisin immunity}

Analysis of the nisin immunity of the L. lactis N8-1 showed that there was significant difference between the mutant and wild-type strains in nisin immunity (Fig. 2a, b). L. lactis N8-1 presented $44.44 \%$ higher nisin resistance than L. lactis N8 (Fig. 2c). The growth curves of the wild-type and mutant strains were obtained under different concentrations of nisin, and revealed that there were no significant differences in growth between the mutant and wild-type strains at $4000 \mathrm{IU} / \mathrm{mL}$ (Fig. 2d), $5000 \mathrm{IU} /$ $\mathrm{mL}$ (Fig. 2e), and $6000 \mathrm{IU} / \mathrm{mL}$ (Fig. 2f) nisin concentrations. These results indicated that the wild-type and mutant strains could grow in GM17 medium with high concentration of nisin [6500 IU/mL (Fig. 2g), $7000 \mathrm{IU} /$ $\mathrm{mL}$ (Fig. 2h), and $7500 \mathrm{IU} / \mathrm{mL}$ (Fig. 2i)]; however, the wild-type strain started to grow was $15-20 \mathrm{~h}$ later than the mutant strain, suggesting that $L$. lactis N8-1 took less time to overcome the side effects of nisin and start to grow. These findings indicated that L. lactis N8-1 has better nisin immunity than L. lactis N8. Moreover, although nisin producers were not killed by high concentrations of nisin to a certain extent, their growth was still restrained.

\section{Mutant strain exhibited increased resistance to lysozyme} The lysozyme tolerance of $L$. lactis $\mathrm{N} 8$ and $L$. lactis N8-1 was evaluated by drop plate experiments. The survival rates of L. lactis N8 and L. lactis N8-1 after lysozyme treatment were determined to clarify the difference between both the strains. The L. lactis N8-1 exhibited higher survival rates after treated with lysozyme at various time points (Fig. 3a). After treatment for $60 \mathrm{~min}$, L. lactis N8-1 exhibited 75.3-fold higher survival rate, when compared with L. lactis N8. Moreover, after treatment for $120 \mathrm{~min}$, the survival rate of $L$. lactis N8-1 was markedly higher (1000-fold) than that of the control strain (Fig. 3b). These results demonstrated that loss of PRF conferred L. lactis N8-1 lysozyme tolerance.

\section{Mutant strain presented increased resistance to lactic acid}

To determine lactic acid tolerance, the growth curves of L. lactis N8 and L. lactis N8-1 under different concentrations of lactic acid were acquired (Fig. 3). There was no significant difference between the OD600 of L. lactis N8 and L. lactis N8-1 when the concentration of lactic acid was $0.24 \%$ (v/v) (Fig. 3e). In contrast, when the concentration of lactic acid was increased to $0.32 \%(\mathrm{v} / \mathrm{v})$, the OD600 of the mutant strain was 58\% higher than that of the wild-type strain after $18 \mathrm{~h}$ of incubation (Fig. 3f). The mutant strain continued to grow, whereas the wild-type strain could hardly grow when the lactic acid concentration was increased to $0.40 \%$ (v/v) (Fig. 3g). Drop plate experiment showed that L. lactis N8-1 exhibited higher survival rates at various time points after being treated with lactic acid $[1.5 \%(\mathrm{v} / \mathrm{v})]$, and the survival rate of $L$. lactis N8-1 was significantly higher than that of L. lactis N8 (10,000-fold) after 60 min of treatment (Fig. 3c, d).

\section{Mutant strains reached higher cell density at high temperature}

To determine the tolerance of the mutant strain to high temperature, the growth curves of L. lactis $\mathrm{N} 8$ and $L$. lactis N8-1 under different temperatures were acquired. There was no significant difference between the OD600 of L. lactis N8 and L. lactis N8-1 when the temperatures were $30{ }^{\circ} \mathrm{C}$ (Fig. 3h) and $37{ }^{\circ} \mathrm{C}$ (Fig. 3i). However, when the temperature was raised to $39{ }^{\circ} \mathrm{C}$, significant difference in the OD600 was observed between L. lactis N8 and L. lactis N8-1 (Fig. 3j). After 9 h, the growth of $L$. lactis N8 drastically decreased, while L. lactis N8-1 could still grow. The growth curves obtained at $39{ }^{\circ} \mathrm{C}$ revealed abnormal L. lactis N8 growth, indicating that high temperature had disrupted its normal growth; in contrast, the growth of L. lactis N8-1 was still normal. 


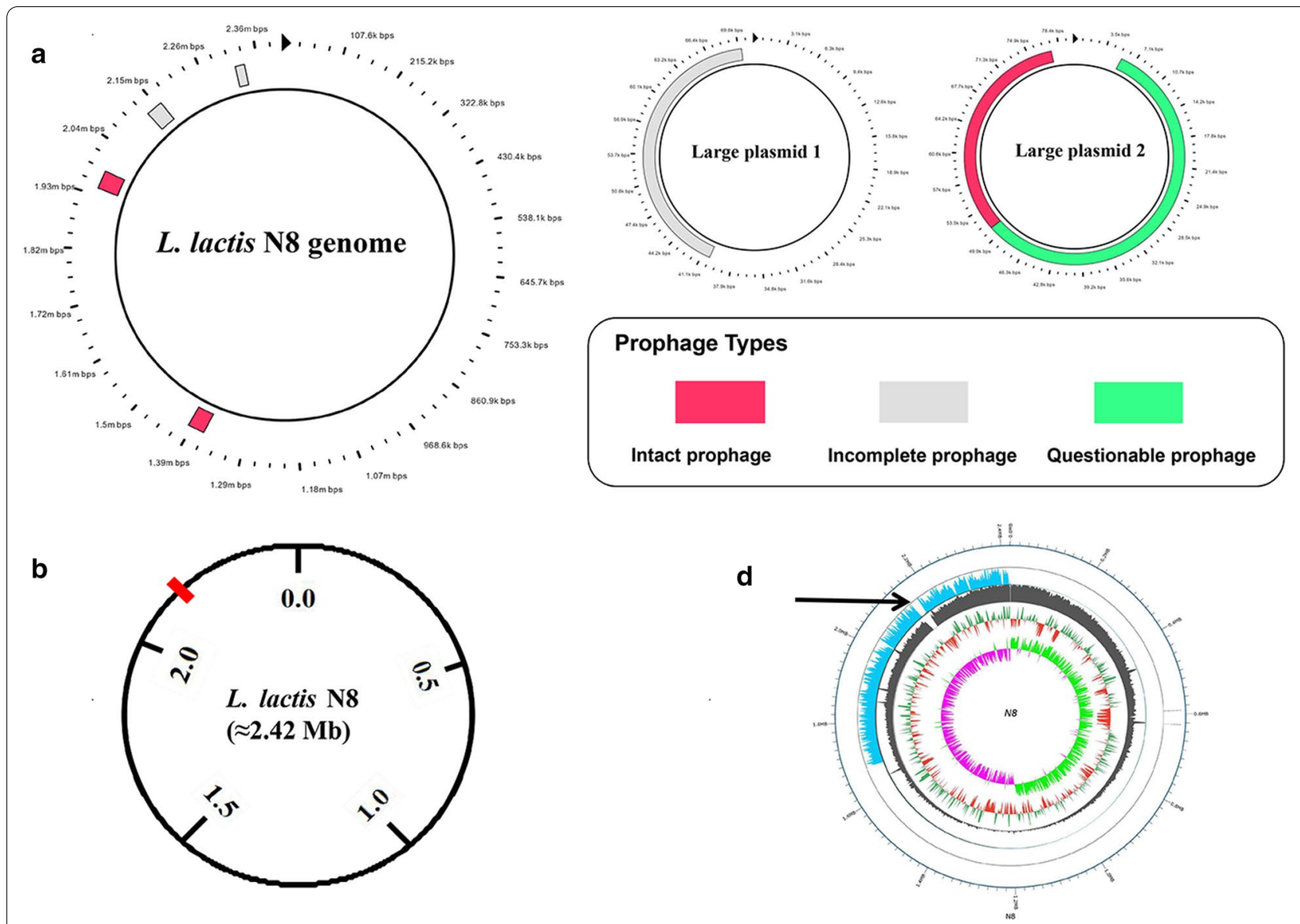

C

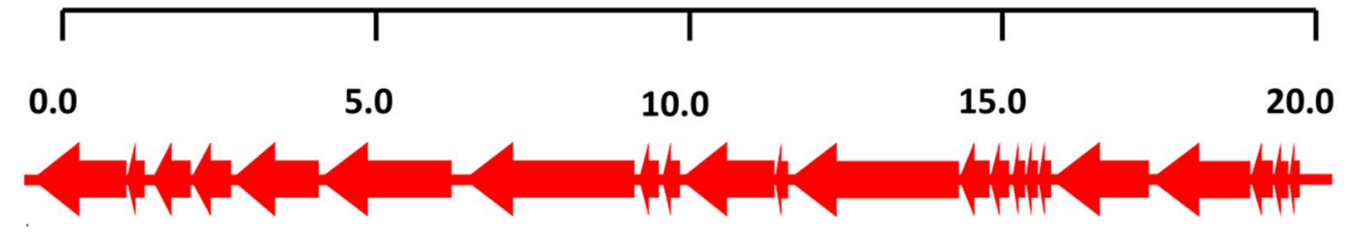

Size c

19.7

e

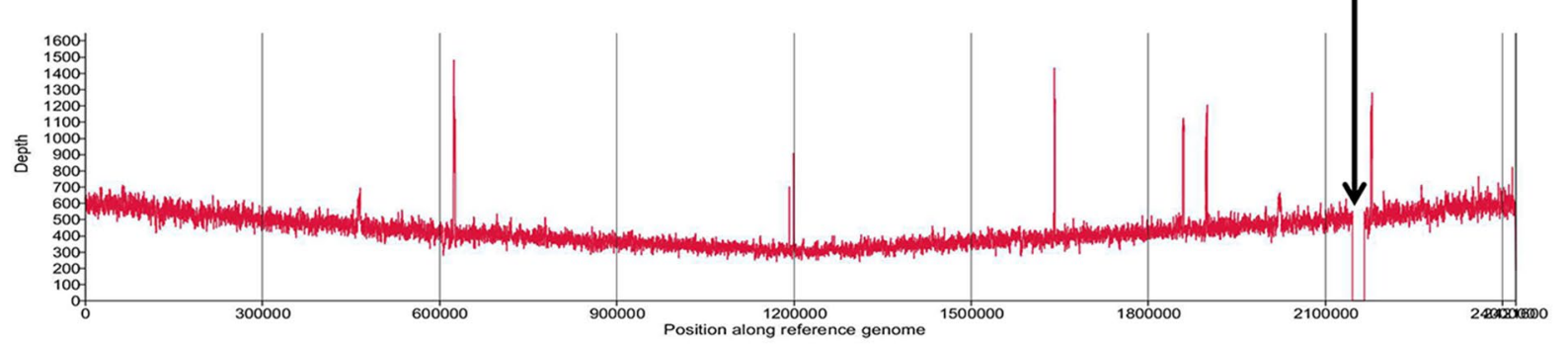

Fig. 1 Circular map of L. lactis N8 chromosome and two large plasmids, and deletion of PRF DNA region in L. lactis N8. a Physical location of the seven PRFs. b Physical location of the deleted PRF in the genome. $\mathbf{c}$ Genetic organization of deleted PRF. $\mathbf{d}$ Resequencing results proved correct knockout. e Alignment of L. lactis N8 and L. lactis N8-1 genome sequences verified correct deletion

Mutant strains showed higher utilization of several carbon sources

Extensive fermentation phenotype analyses of $L$. lactis N8-1 and L. lactis N8 were conducted using the phenotype microarrays to further understand the physiological differences between the wild-type and mutant strains. Additional file 1: Table S2 summarizes the comparisons of substrates consumed by L. lactis N8-1 and L. lactis N8. The results showed that the mutant strain could efficiently metabolize 


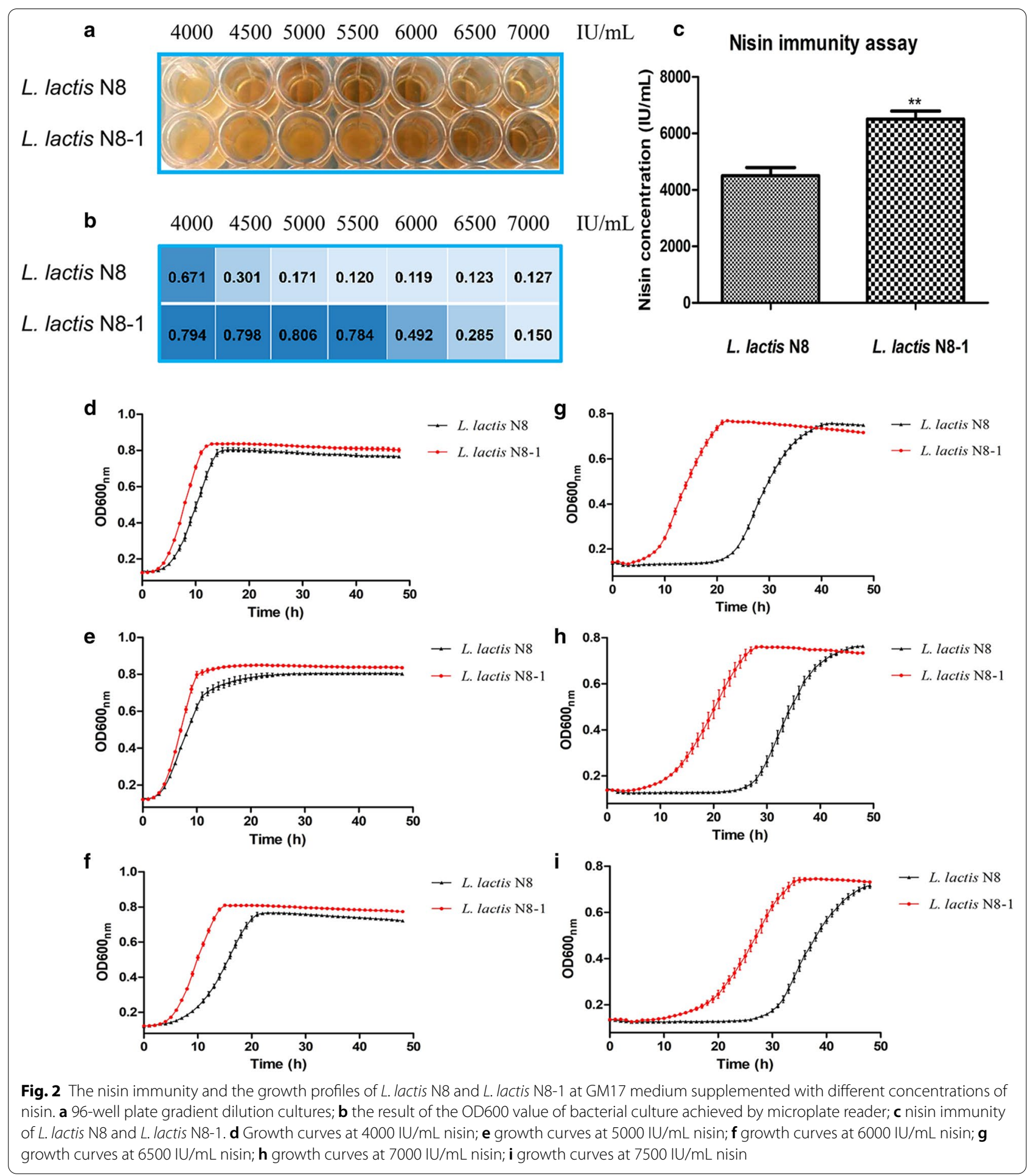

some substrates, including $\alpha$-D-glucose, D-mannose, sucrose, and $N$-acelyl-D-glucosamine, which are associated with carbon source metabolism and cell wall biosynthesis. The mutant $L$. lactis N8-1 exhibited distinct properties with respect to metabolism of four carbon sources, when compared with the wild-type strain. 


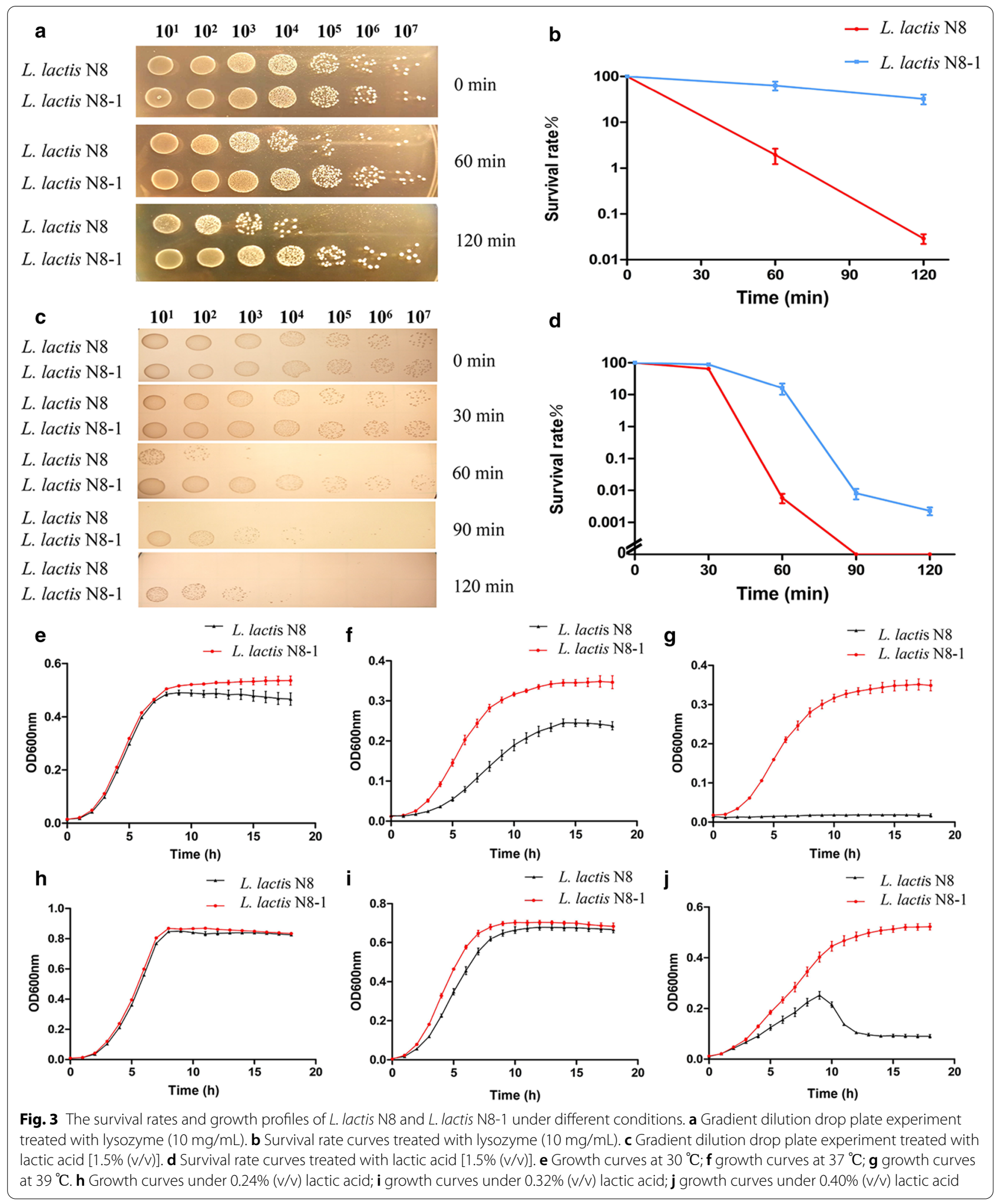




\section{Scanning electron microscopy of cells after lysozyme treatment}

To determine the causes of multi-stress tolerance of the mutant $L$. lactis N8-1, the morphology and cell integrity of L. lactis N8 and L. lactis N8-1 after lysozyme treatment were examined by scanning electron microscopy (SEM). As shown in Fig. 4, following lysozyme treatment $(17.5 \mathrm{mg} / \mathrm{mL}$ ) for $60 \mathrm{~min}$, the cell wall of $L$. lactis N8-1 maintained better integrity, whereas that of L. lactis N8 presented obvious holes. After $120 \mathrm{~min}$ of lysozyme treatment, the cell wall of $L$. lactis N8-1 was damaged, while that of $L$. lactis N8 was almost completely degraded. These results (from a micro-perspective) revealed that the cell wall of the mutant $L$. lactis N8-1 was more resistant to lysozyme, and confirmed that L. lactis N8-1 exhibited better robustness.

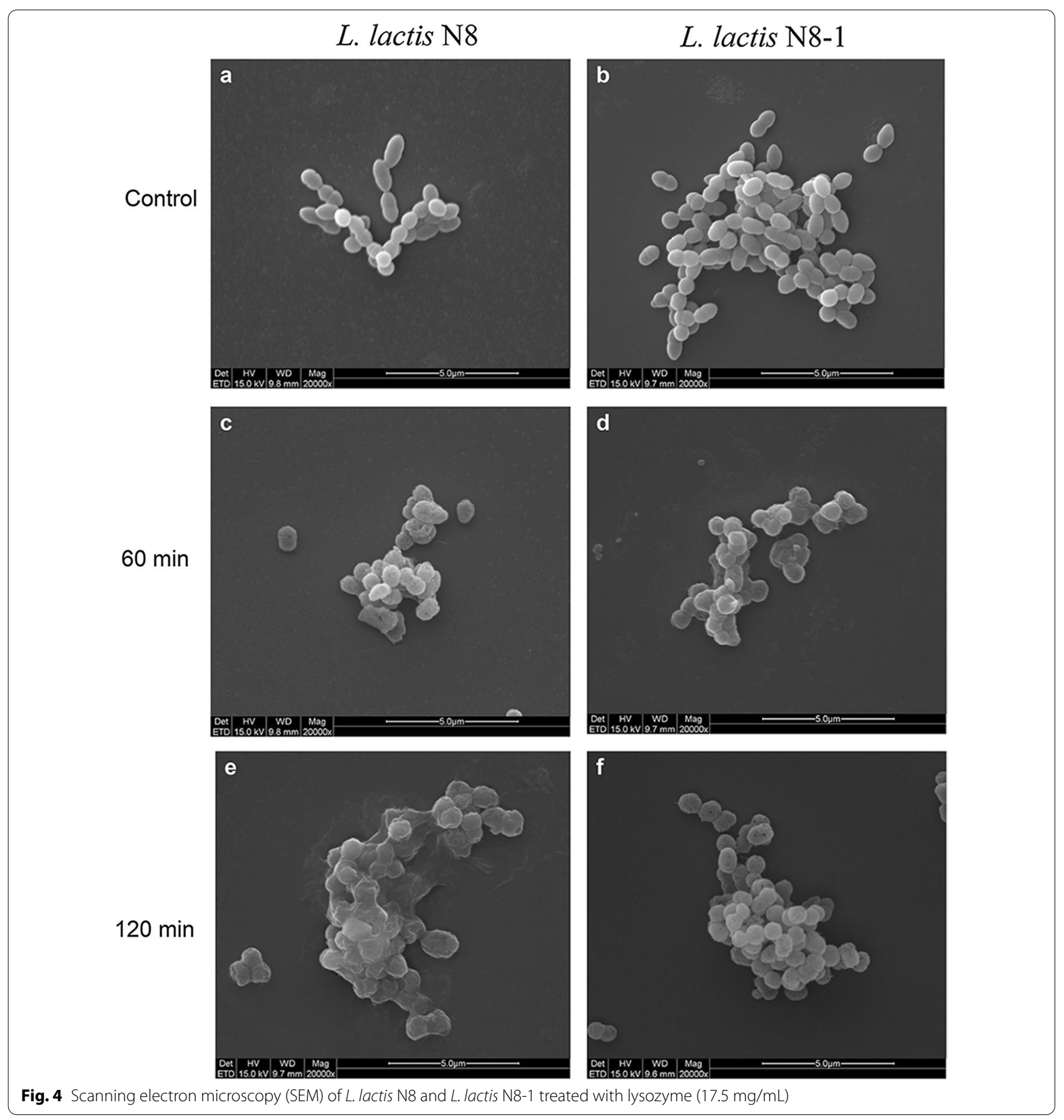




\section{Mutant strains achieved higher nisin yield under acidification conditions}

To obtain strains with superior nisin immunity and nisin production, we constructed engineered strains to obtain a high nisin yield chassis. However, after overexpressing the nisin immunity genes, nisFEG, nisIFEG, and nisRKFEG, in L. lactis N8-1, we were unable to obtain mutant strains with higher nisin immunity characteristics (Additional file 1: Table S3). As strains used in industrial production are known to endure acid stress, we used lactic acid to adjust the $\mathrm{pH}$ of the medium for constant-pH fermentation. As shown in Fig. 5a, there was no obvious difference in nisin production between L. lactis N8 and L. lactis N8-1 when the $\mathrm{pH}$ of the medium was 6.0. However, when the medium $\mathrm{pH}$ was adjusted to 5.5, the nisin yield of L. lactis N8-1 was $36.29 \%$ higher than that of L. lactis N8 at $12 \mathrm{~h}$ (Fig. 5b). When the $\mathrm{pH}$ of the medium was adjusted to 5.0, L. lactis N8 had limited growth with no increased nisin production, while the growth of L. lactis N8-1 was significantly restrained, but presented considerable nisin production (Fig. 5c). Subsequently, we overexpressed nisZ in L. lactis N8-1 and L. lactis N8 and found that the nisin yield of L. lactis N8-1 was $22.57 \%$ and $18.79 \%$ higher than those of the wild-type strain at 10 and 12 h, respectively. (Fig. 5d). These results indicated that L. lactis N8-1 is more advantageous than $L$. lactis N8 as a microbial cell factory with higher nisin yield and nisin immunity.

\section{TMT quantitative proteomics analysis and transcription verification}

The mutant strain L. lactis N8-1 with improved nisin immunity and multi-stress tolerance (lysozyme, lactic acid, and high-temperature tolerance) was constructed. Based on the results of TMT quantitative proteomics, a total of 2164 proteins were detected. Different databases were used to annotate proteins, while KEGG database was used to classify the proteins (Fig. 6a, b). We found that 33 proteins were significantly upregulated and nine proteins were significantly downregulated ( $>1.5$-fold change with $P<0.05)$ in $L$. lactis N8-1, when compared with those in L. lactis N8 (Fig. 6c). The upregulated proteins and downregulated proteins ( $>1.2$-fold change with a $P<0.05)$ are listed in Additional file 1: Tables S4, $\mathrm{S} 5$, respectively. KEGG functional enrichment analysis (L. lactis N8-1 vs L. lactis N8) showed that the upregulated proteins were mainly related to sugar metabolism and amino acid biosynthesis/metabolism (Additional file 1: Fig. S1a). In contrast, the downregulated proteins were mainly related to ribosome biosynthesis (Additional file 1: Fig. S1b). The gene ontology (GO) function annotations for all proteins (and upregulated and downregulated proteins) are shown in Additional file 1: Fig.
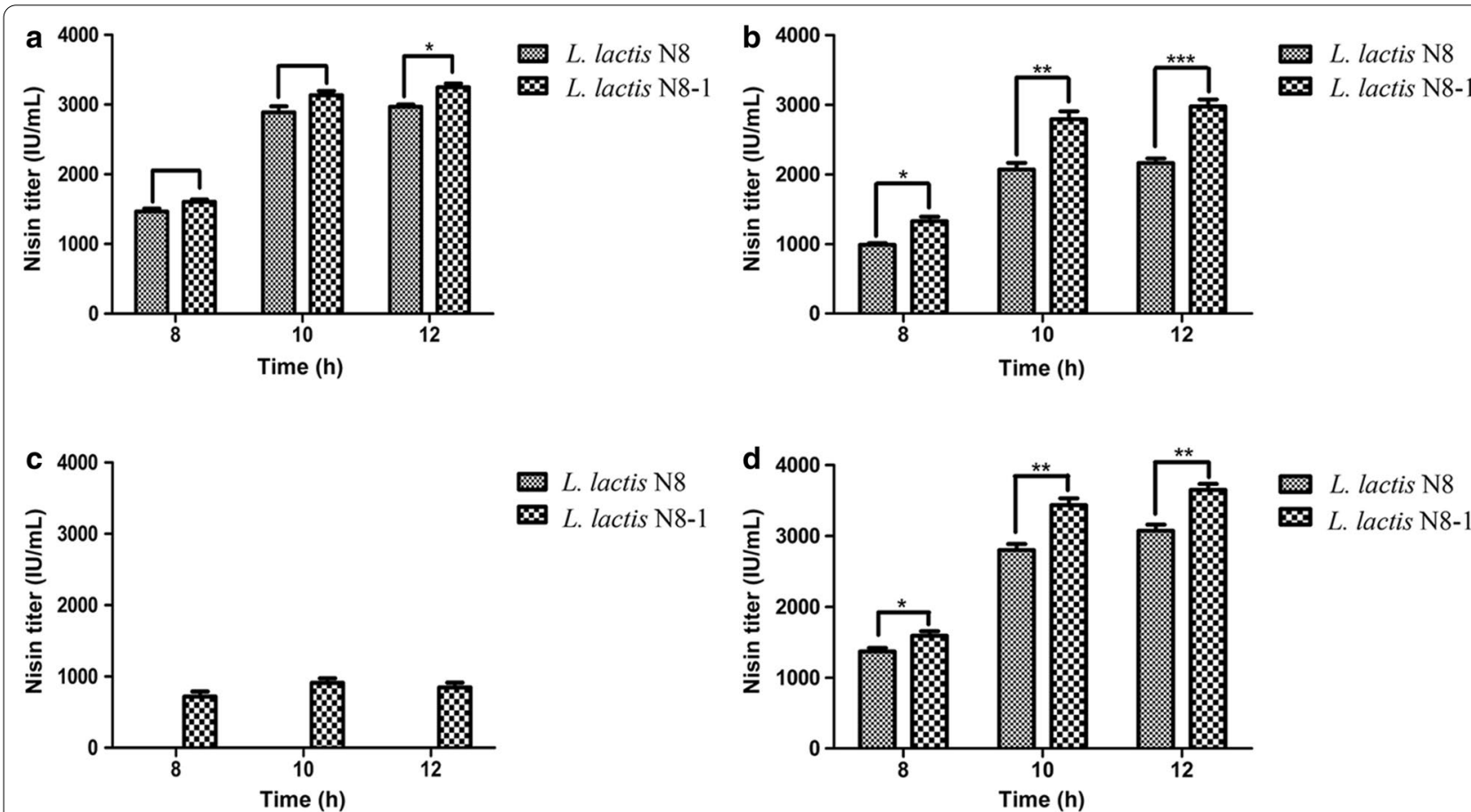

Fig. 5 Comparison of the nisin yield of L. lactis N8 and L. lactis N8-1. a Nisin yield at pH 6.0; b Nisin yield at pH 5.5; c Nisin yield at pH 5.0; d Nisin yield of the wild-type and mutant strains by overexpressing nis $Z$ 


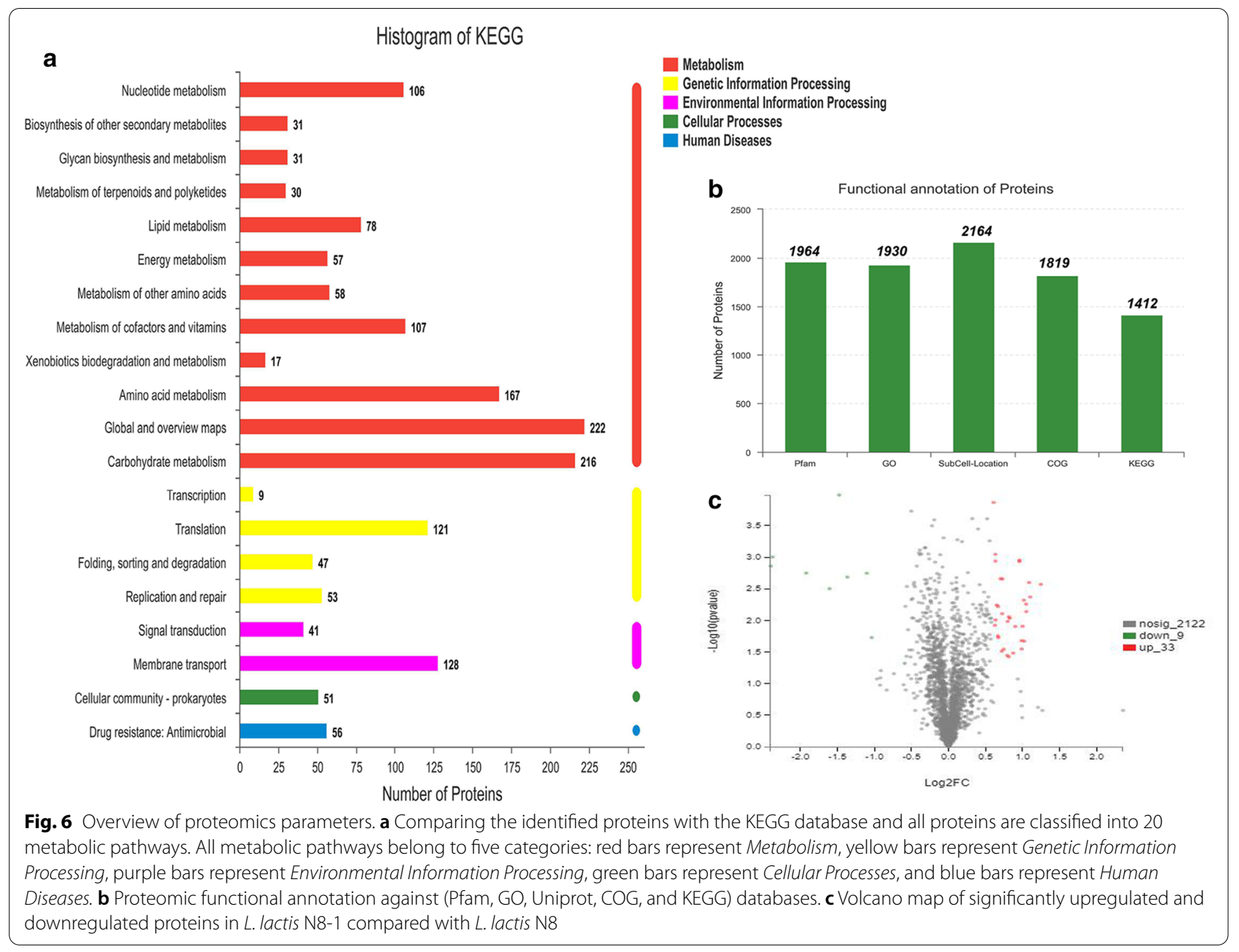

S2. Protein subcellular localization analysis showed that the upregulated proteins were mainly sub-located in the cytoplasm and extracellular (43 proteins), whereas the downregulated proteins were mainly sub-located in the cytoplasm (34 proteins) (Additional file 1: Fig. S3). Subsequently, several genes with higher and lower expression levels were examined by real-time quantitative PCR (RTqPCR) to verify the proteomics data. When compared with $L$. lactis $\mathrm{N} 8$, the expression levels of genes $r p s N$, $r p l R, \csc 2 B, \csc 2 C$, pi339, pp423, butA, butB, arcA, arcB, galM, galK and lacZ were altered in L. lactis N8-1 (about 0.37-, 0.32-, 2.55-, 3.17-, 3.00-, 3.79-, 3.52-, 2.20-, 3.51-, 2.37-, 4.49-, 5.60-, and 2.55-fold, respectively) (Additional file 1: Fig. S4), which were in agreement with the results of proteomics assay.

\section{Discussion}

In laboratory or industrial fermentation process, microbial strains are generally believed to endure many harsh conditions, including oxidation, heating and cooling, acid, high osmolarity/dehydration, and starvation [33]. Therefore, understanding of the stress response behavior of L. lactis is of crucial significance for expanding its application in industrial fermentation. In recent years, an increasing number of studies have confirmed that $L$. lactis can survive by activating specific protection mechanisms in response to environmental pressure [34]. To tolerate heat shock, L. lactis regulates the folding and maturation of new or denatured proteins through the synthesis of heat shock proteins (HSPs). Genetic analyses have confirmed the presence of the conserved HSPs in $L$. lactis, including DnaK, DnaJ, GroEL, GroES, and GrpE [33]. Under low temperature pressure, E. coli can prevent the formation of secondary structures in RNA molecules and stimulate translation efficiency by regulating the cold shock proteins (CSPs), CspA [35]. Researchers have identified conserved CSPs (CspA, CspB, CspC, CspD, and $\mathrm{CspE}$ ) in L. lactis and proved the important role of these CSPs under cold shock conditions [36]. Under low $\mathrm{pH}$ condition, LAB mainly employ two mechanisms to 
respond to stimuli. The primary mechanism for the control of intracellular $\mathrm{pH}$ is $\mathrm{F}_{0} \mathrm{~F}_{1}$ ATPase that translocates protons to the environment at the expense of ATP. Both the expression level and activity of this protein complex have been noted to increase at low $\mathrm{pH}$ [37]. The second mechanism in response to low $\mathrm{pH}$ is the arginine deiminase pathway that allows $L$. lactis to neutralize its environment through $\mathrm{NH}_{3}$ production [38]. To overcome oxidative stress, some L. lactis strains have been reported to accumulate glutathione and possibly utilize glutathione to remove $\mathrm{O}_{2}^{-}[39,40]$. Conversely, the expression of recA has been noted to be induced in aerated cultures and a recA mutant $L$. lactis has been found to be highly sensitive to aeration, indicating that $r e c A$ gene clearly plays a role in oxidative stress [41]. In the past decades, numerous studies have been conducted to improve strain stress tolerance, and heterologous expression and overexpression in LAB have gained much research attention. Sugimoto et al. constructed multi-stress tolerant (3\% $\mathrm{NaCl}, 5 \%$ ethanol, and $0.5 \%$ lactic acid) L. lactis NZ9000 by heterologous expression of dnaK gene from $E$. coli [42]. Hagi et al. proved that the heterologous expression of crtNM in L. lactis MG1363 led to the increased $\mathrm{H}_{2} \mathrm{O}_{2}$, low $\mathrm{pH}, 20 \%$ bile acid, and $12 \mathrm{mg} / \mathrm{mL}$ lysozyme tolerance [43]. Furthermore, Desmond et al. improved stress tolerance by overexpressing GroESL in Lactobacillus paracasei NFBC 338 [solvent tolerance, the ability to grow in the presence of butanol $(0.5 \% \mathrm{v} / \mathrm{v})$ for $5 \mathrm{~h}$ ] [11], while $\mathrm{Zhu}$ et al. overexpressed ABC transporters in L. lactis NZ9000 and obtained enhanced acid-stress tolerance derivatives [44]. The common strategy that had been applied in these studies is the so-called "plus" method to achieve high synthesis level of the target proteins. In contrast, large non-essential fragments, such as prophages, transposons, and genomic islands, as exogenously inserted chromosomal sequence, are not necessary for the host cells. It has been reported that deletion of large non-essential fragments produced the phenotypes with reduced metabolic burden, faster growth, and increased biomass [4]. Therefore, the "minus" method could be considered as a promising approach.

In the present study, after deleting a PRF, the mutant strain L. lactis N8-1 did not show growth deficiency, when compared with the wild-type strain. Besides, the genome of the mutant strain L. lactis N8-1 was streamlined, which is beneficial for the construction of engineered LAB microbial cell factories. The mutant $L$. lactis N8-1 exhibited significantly improved nisin immunity, which may provide a good basis for achieving high production of nisin. Proteomics analysis showed that the synthesis of NisI and NisFEG proteins was not increased in the mutant strain. Subsequently, we tried to overexpress the genes nisFEG, nisIFEG and nisRKFEG in $L$. lactis N8-1; however, no strains with significantly higher nisin immunity were obtained, indicating that beyond a certain range, nisin immunity tends to be under a global and complex regulation.

Besides the substantial increment in nisin immunity, the mutant strains also presented heat, lactic acid, and lysozyme resistances. We speculated that the improved multi-stress tolerance of the mutant strains was owing to the loss of PRF, resulting in remodeling of the cell wall/ membrane and changes in carbon source metabolism. Previous studies have shown that the structure of the cell wall/membrane affects the nisin tolerance of LAB [45], and cell wall, as the first barrier of bacteria, is essential for the strain's stress tolerance [20]. Similarly, in the present study, the synthesis levels of enzymes related to cell wall/membrane biosynthesis and degradation in L. lactis N8-1 were noted to be altered. Thus, combined with the results of lysozyme treatment experiment and SEM, these evidences demonstrated that deletion of PRF resulted in remodeling of the mutant's cell wall/membrane. Based on the possible pleiotropic changes caused by PRF knockout, the proteins that led to stress tolerance in the mutant strain could be discussed in the following three groups: (1) carbohydrate and energy transport/metabolism; (2) synthesis of peptidoglycan (PG), cell wall, and cell surface proteins; and (3) others (Table 1). The findings of this study could help us to further understand the possible mechanism of stress tolerance of L. lactis, and lay a foundation to explore the deeper and detailed underlying reasons in the future as well as provide significant guidelines for the construction of robust microbial cell factories.

\section{Carbohydrate and energy transport/metabolism}

Carbohydrate and energy transport/metabolism are the basic life activities of bacteria. Changes in the synthesis of enzymes that catalyze these processes often produce a huge impact on the bacterial phenotype. The proteomics results of the present study indicated that the protein synthesis levels of GalM (aldose 1-epimerase), GalK (galactokinase), and GalT (galactose-1-phosphate uridylyltransferase), which belong to galactose metabolism pathway, were significantly upregulated in L. lactis N8-1. The upregulation of these proteins allowed the metabolic flow to $\alpha-D-$ glucose 1-phosphate, which can be used as an intermediate substrate to participate in glycolysis, pentose and glucuronate interconversions, etc. As the intermediate product of glycolysis, pyruvate participates in sugar metabolism, amino acid metabolism, citrate cycle, and fatty acid metabolism. Previous studies have shown that the gal operon plays a role in the nisin tolerance, and that L. lactis NZ9000 $\triangle$ galAMK 
Table 1 Partial upregulated proteins found in proteomic analysis (L. lactis N8-1 vs L. lactis N8)

\begin{tabular}{|c|c|c|c|}
\hline Protein name & Description & fc (N8-1/N8) & $P$-value (N8-1/N8) \\
\hline \multicolumn{4}{|c|}{ Carbohydrate and energy transport/metabolism } \\
\hline GalM & Aldose 1-epimerase & 1.8319 & 0.0328 \\
\hline GalK & Galactokinase & 1.9828 & 0.0283 \\
\hline GalT & Galactose-1-phosphate uridylyltransferase & 1.6774 & 0.0286 \\
\hline LacA & Galactoside O-acetyltransferase & 1.6464 & 0.0307 \\
\hline LacZ & Beta-galactosidase & 1.7593 & 0.0376 \\
\hline LacS & Lactose and galactose permease GPH translocator family & 1.5916 & 0.0060 \\
\hline \multicolumn{4}{|c|}{ Biosynthesis/degradation of PG, cell wall and cell surface proteins } \\
\hline YmjE & Glycosyl transferase & 1.5957 & 0.0187 \\
\hline YmjF & UDP-N-acetylglucosamine 2-epimerase & 2 & 0.0123 \\
\hline YuaE & Aspartate protease & 1.5713 & 0.0057 \\
\hline ChiA & Chitinase & 1.6291 & 0.0021 \\
\hline YqcD & WxL domain-containing protein & 2.0262 & 0.0047 \\
\hline $\operatorname{Csc} 2 \mathrm{~A}$ & Cell surface protein & 1.5525 & 0.0011 \\
\hline $\operatorname{Csc} 2 B$ & WxL domain-containing cell surface protein & 2.1488 & 0.0042 \\
\hline $\operatorname{Csc} 2 \mathrm{C}$ & WxL domain-containing cell surface protein & 1.8678 & 0.0124 \\
\hline YqbH & Transcriptional regulator & 1.7327 & 0.0358 \\
\hline YbeF & Collagen binding domain-containing protein & 2.3745 & 0.0026 \\
\hline \multicolumn{4}{|c|}{ Others (phage-related proteins) } \\
\hline Pip & Phage infection protein & 1.9826 & 0.0209 \\
\hline NA & Phage antirepressor & 1.5872 & 0.0176 \\
\hline Pp261 & Uncharacterized protein & 1.5545 & 0.0098 \\
\hline Pi339 & Prophage pi3 protein 39 & 1.7602 & 0.0087 \\
\hline Pp423 & Phage transcriptional regulator, ArpU family & 1.9412 & 0.0011 \\
\hline Phi3396 & Phage major capsid protein & 1.6566 & 0.0022 \\
\hline NA & Phage tail protein & 1.9425 & 0.0011 \\
\hline NA & Prophage protein & 1.6534 & 0.0078 \\
\hline Pi308 & Prophage pi3 protein 34 & 1.7759 & 0.0092 \\
\hline YjaE & YhgE/Pip (phage infection protein) domain-containing protein & 2.0323 & 0.0212 \\
\hline
\end{tabular}

was twice as sensitive to nisin as its parent strain [46]. However, the contributions of the mechanisms of these transport systems to stress resistance remain to be elucidated. It has been speculated that sugar metabolism intermediates in cell wall biosynthesis or PTS systems might contribute to energy for stress tolerance mechanism [46]. In the present study, the synthesis level of LacZ ( $\beta$-galactosidase), LacA (galactoside $\mathrm{O}$-acetyltransferase), and LacS (lactose permease) was significantly upregulated in L. lactis N8-1. LacZ catalyzes the hydrolysis of terminal nonreducing $\beta$-D-galactose residues in $\beta$-D-galactosides, while LacA and LacS are sugar transport proteins. The proteins of this family are major facilitators of membrane transport and may contribute to energy supply in stress tolerance mechanism. Overall, all these mechanisms above could contribute to the ability of the mutant strains to completely utilize carbon source and may provide a basis for the strain's multistress tolerance.

2. Biosynthesis of PG, cell wall and cell surface proteins Cell wall is essential for stress tolerance in bacteria. Under constantly changing living conditions, enzymes that are involved in PG synthesis and degradation can regulate the dynamic balance of the strain's cell wall. In L. lactis N8-1, YmjE (glycosyl transferase) and YmjF (UDP-N-acetyl glucosamine 2-epimerase), which are essential for the biosynthesis of cell wall surface polysaccharides [47], were significantly upregulated. Cell wall surface polysaccharides have been confirmed to contribute to nisin immunity of LAB [25]. In L. lactis N8-1, synthesis of cell surface proteins, Csc $2 \mathrm{~A}, \mathrm{Csc} 2 \mathrm{~B}$, and $\mathrm{Csc} 2 \mathrm{C}$, were significantly upregulated. Siezen et al. speculated that the proteins from cell surface protein complexes may play an important role in carbon source acquisition 
of bacteria [48]. The gene from $\csc A B C D$ gene cluster encodes WxL-domain-containing cell surface proteins and LPxTG-anchored cell surface proteins. The WxL motif confers protien cell surface localization function, and this region is the cell wall-binding domain of Gram-positive bacteria and may interact with PG [49]. Besides, the synthesis of YbeF (LPxTG collagen binding domain-containing protein) in L. lactis N8-1 was significantly increased. Pieterse et al. showed that the synthesis of LPxTG-anchored cell surface protein was significantly improved after treatment with lactic acid [50], suggesting that LPxTG-anchored cell surface protein contributes to lactic acid resistance. As these two proteins are anchored on the cell wall/membrane to some extent, we proposed that the cell surface proteins are likely to participate in the stress tolerance of the strain and further protect it. The synthesis and degradation of cell wall is a precise regulation process and maintains certain balance [51]. We speculated that the deletion of PRF could promote remodeling of cell wall, which may eventually make the cell wall become denser or form a protective structure, ultimately providing multi-stress tolerances.

3. Others

In addition to the above-mentioned changes, the synthesis levels of 9 proteins belonging to a complete prophage were significantly upregulated in the mutant strain. Besides, the synthesis of several other bacteriophage infection proteins was also upregulated. A previous study had demonstrated that $L$. lactis IL1403 acquired stress tolerance (antimicrobial, heme) after deleting all the prophages [23]; however, the study did not clarify the changes in the strain at the transcriptional or translational level; therefore, it is difficult to determine the prophage that conferred stress tolerance to the strain. In the present study, comparison of the PRF deleted from L. lactis N8 with all the PRFs of L. lactis IL1403 revealed no correlation, indicating that deletion of different types of PRF confers diverse characteristics to the strain. However, protein synthesis of a prophage that still remained on the mutant's genome was increased, suggesting that the absence of a certain type of PRF could affect the protein synthesis of other prophages even in the lysogenic state. It is presumed that recognition and competition mechanisms of the prophages could ultimately affect the phenotype of the strain itself.

Thus, it can be concluded that the acquired multistress tolerance of the mutant strain L. lactis N8-1 is a very complex trait. Figure 7 summarizes the simplified metabolic pathways. Many proteins possibly involved in stress tolerance were detected and two major mechanisms of acquiring stress tolerance could hypothesized. The first mechanism of acquiring stress tolerance could possibly be through changes in protein synthesis of prophage, with lysophage indirectly contributing to the stress tolerance of the host bacteria; however, detailed reason still needs to be explored. The second and major mechanism could be the changes in the cell wall structure. The cell wall of the L. lactis N8-1 might have probably been altered in two ways: becoming denser (LacS, YmjE, YmjF) and getting thicker (Csc2A, Csc2B, Csc2C).

\section{Conclusions}

This study demonstrated that bacterial cells employ diverse mechanisms to defend themselves against multiple stresses. To the best of our knowledge, this is the first report to improve the multi-stress tolerance and nisin immunity of $L$. lactis by deleting PRF. TMT quantitative proteomics was proven to be an efficient technique to systematically and comprehensively elucidate the possible mechanisms of multi-stress tolerance of PRF knockout strain, which provides a new strategy for industrially obtaining robust L. lactis microbial cell factories with superior tolerance and higher nisin immunity.

\section{Methods}

\section{Bacterial strains, plasmids and growth conditions}

The strains and plasmids used in this study are listed in Table 2. L. lactis N8 (wild-type nisin $\mathrm{Z}$ producer) and its derivatives were cultured at $30{ }^{\circ} \mathrm{C}$ without agitation in GM17 medium [M17 broth supplemented with 0.5\% $(\mathrm{w} / \mathrm{v})$ glucose]. E. coli $\mathrm{DH} 5 \alpha$ cells were grown aerobically at $37{ }^{\circ} \mathrm{C}$ in Luria-Bertani (LB) broth (1\% tryptone, $0.5 \%$ yeast extract, and $1 \% \mathrm{NaCl}$ ) and used as cloning host. Micrococcus luteus NCIB 8166 was cultured aerobically in LB Broth at $37{ }^{\circ} \mathrm{C}$ and used as nisin sensitive indicator strain to detect the antibacterial activity of nisin. $L$. lactis NZ9000 was used as intermediate cloning host for the pNZ8048/pLEB124 plasmids construction, and it was cultured at $30{ }^{\circ} \mathrm{C}$ without agitation in GM17 medium. While pNZ8048/pLEB124 was used to construct the expression vector, pNZ5319 was employed to construct the knock-out vector through Cre-loxP gene recombination system. Antibiotics were used when needed: 150 and $5 \mu \mathrm{g} / \mathrm{mL}$ erythromycin for $E$. coli and L. lactis, respectively; 15 and $5 \mu \mathrm{g} / \mathrm{mL}$ chloramphenicol for $E$. coli and $L$. lactis, respectively; $100 \mu \mathrm{g} / \mathrm{mL}$ kanamycin for $E$. coli; and $20 \mu \mathrm{g} / \mathrm{mL}$ ampicillin for L. lactis.

\section{DNA manipulations and cloning}

Restriction enzymes, DNA markers, DNA ligase, DNA polymerases and DNA gel extraction kit were purchased from Takara Bio. Inc. (Dalian, China). Bacterial genome 


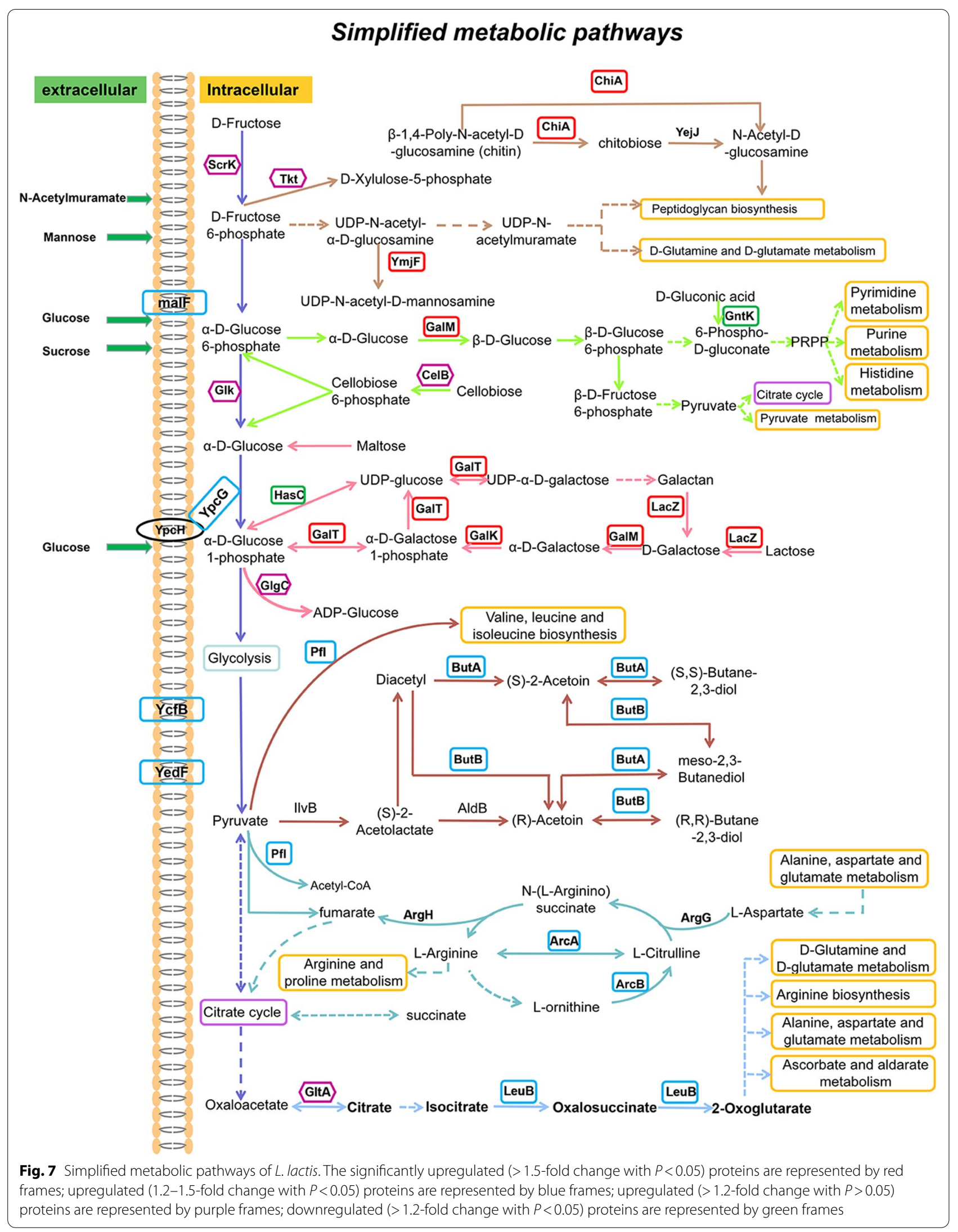


Table 2 Bacterial strains and plasmids utilized in this study

\begin{tabular}{|c|c|c|}
\hline Strains or plasmids & Relevant descriptions & Reference \\
\hline \multicolumn{3}{|l|}{ Strains } \\
\hline E. coli DH5a & $\begin{array}{l}\text { Cloning host; F- } \varphi 80 \text { lac } Z \triangle M 15 \text { endA1 recA1 endA1 hsdR17 (rK-mK+) supE44 thi-1 gyrA } 96 \text { relA1 } \\
\triangle \text { (lacZYA-argF)U169 deoR } \lambda \text { - }\end{array}$ & [58] \\
\hline E. coli DH5a-up & $\mathrm{Cm}^{r}, \mathrm{Em}^{r}$, E. coli DH5a derivative containing the whole plasmid pNZ5319-up & This study \\
\hline E. coli DH5a-up-down & $\mathrm{Cm}^{r}$, Emr', E. coli DH5a derivative containing the whole plasmid pNZ5319-up-down & This study \\
\hline Micrococcus /uteus NCIB 8166 & Indicator strains for Nisin agar gel diffusion assay & [59] \\
\hline L. lactis NZ9000 & MG1363 pepN::nisRK & [60] \\
\hline L. lactis N8 & Wild-type (WT) Nisin Z producer & [27] \\
\hline L. lactis N8-up-down & $\begin{array}{l}\mathrm{Cm}^{r} \text {, Em}{ }^{r} \text {, L. lactis N8 derivative containing the whole plasmid pNZ5319-up-down (single cross- } \\
\text { over) }\end{array}$ & This study \\
\hline L. lactis N8-cat & $\begin{array}{l}\mathrm{Cm}^{r} \text {,L. lactis N8 derivative containing the a lox66-P32-cat-lox71 replacement of PRF (double cross- } \\
\text { over) }\end{array}$ & This study \\
\hline L. lactis N8-1 & Mutant. The PRF deletion from L. lactis N8 & This study \\
\hline L. lactis N8-vector1 & $\mathrm{Cm}^{r}$, L. lactis N8 derivative containing pNZ8048 & This study \\
\hline L. lactis N8-nisZ & $\mathrm{Cm}^{r}$, L. lactis N8 derivative containing pNZ8048-nisZ & This study \\
\hline L. lactis N8-1-vector1 & $\mathrm{Cm}^{r}$, L. lactis N8-1 derivative containing pNZ8048 & This study \\
\hline L. lactis N8-1-nisZ & $\mathrm{Cm}^{r}$, L. lactis N8-1 derivative containing pNZ8048-nisZ & This study \\
\hline L. lactis N8-vector2 & $\mathrm{Em}^{r}$, L. lactis N8 derivative containing pLEB124 & This study \\
\hline L. lactis N8-nisFEG & $\mathrm{Em}^{\mathrm{r}}$, L. lactis N8 derivative containing pLEB672 & This study \\
\hline L. lactis N8-nisIFEG & $\mathrm{Em}^{\mathrm{r}}$, L. lactis N8 derivative containing pLEB124-nisIFEG & This study \\
\hline L. lactis N8-nisRKFEG & $\mathrm{Em}^{\mathrm{r}}$, L. lactis N8 derivative containing pLEB674 & This study \\
\hline L. lactis N8-1-vector2 & $\mathrm{Em}^{r}$, L. lactis N8-1 derivative containing pLEB124 & This study \\
\hline L. lactis N8-1-nisFEG & $\mathrm{Em}^{r}$, L. lactis N8-1 derivative containing pLEB672 & This study \\
\hline L. lactis N8-1-nisIFEG & $\mathrm{Em}^{r}$, L. lactis N8-1 derivative containing pLEB124-nisIFEG & This study \\
\hline L. lactis N8-1-nisRKFEG & $\mathrm{Em}^{r}$, L. lactis N8-1 derivative containing pLEB674 & This study \\
\hline \multicolumn{3}{|l|}{ Plasmids } \\
\hline pNZ5319 & $\mathrm{Cm}^{r}, \mathrm{Em}^{r}$, used as knock-out vector & [31] \\
\hline pNZ5319-up & $\mathrm{Cm}^{r}$, Em', upstream homology arm amplified from L. lactis N8 genome cloned into pNZ5319 & This study \\
\hline pNZ5319-up-down & $\begin{array}{l}\mathrm{Cm}^{r} \text {, Em }{ }^{r} \text {, upstream and downstream homology arm amplified from L. lactis N8 genome cloned } \\
\text { into pNZ5319 }\end{array}$ & This study \\
\hline pNZTS-Cre & $\mathrm{Em}^{\mathrm{r}}$, cre gene cloned at the EcoRI and Hindlll sites (cat gene deletion vector) & [53] \\
\hline pNZ8048 & $\mathrm{Cm}^{r}$, pNZ8048 derivative containing the promoter P8 & [61] \\
\hline pNZ8048-nisZ & $\mathrm{Cm}^{r}$, pNZ8048 derivative containing the promoter P8/nisZ & [61] \\
\hline pLEB124 & $\mathrm{Em}^{\mathrm{r}}$, L. lactis secretion vector harboring lactococcal promoter P45 & [27] \\
\hline pLEB672 & $\mathrm{Em}^{r}$, pLEB124 derivative containing the nisFEG gene & [62] \\
\hline pLEB124-nisIFEG & $\mathrm{Em}^{r}$, pLEB124 derivative containing the nis/FEG gene & From Per Saris'lab \\
\hline pLEB674 & $\mathrm{Em}^{\mathrm{r}}$, pLEB124 derivative containing the nisRKFEG gene & [62] \\
\hline
\end{tabular}

rapid extraction part A kit was purchased from Spark Jade (China). Polymerase chain reaction (PCR) product purification kit was purchased from Thermo Fisher Scientific (Waltham, USA). The commercial nisin was purchased from Sigma (St. Louis, USA). Chromosomal DNA plasmid DNA, and total RNA of L. lactis N8 or E. coli were isolated using QIAprep spin kit (small scale) following the manufacturer's instructions. PCR was performed on Bio-Rad S1000 Thermal Cycler (Bio-Rad Laboratories, Inc. USA). Primers used in this study were purchased from GENEWIZ (Suzhou, China), and are listed in
Table 3. Recombinant plasmids were introduced into $L$. lactis by electroporation using the Bio-Rad Gene Pulser (Bio-Rad Laboratories, Richmond, USA). Plasmids were introduced into $E$. coli through the $\mathrm{CaCl}_{2}$ method [52].

\section{Deletion of PRF DNA region}

The vector for the deletion of the PRF was constructed as described in our previous work [53]. Briefly, two fragments (upstream homology arm 1555 bp, downstream homology arm $1414 \mathrm{bp}$ ) of the flanking region of PRF were amplified by PCR with a proof-reading polymerase 
Table 3 Primers used in this study

\begin{tabular}{|c|c|}
\hline Primers & Sequence $\left(5^{\prime}-3^{\prime}\right)$ \\
\hline \multicolumn{2}{|c|}{ For the construction of deletion vector (pNZ5319-up-down) } \\
\hline Up-f & CCGCTCGAGTTAATCGGTGGTGTTACTACTGG \\
\hline Up-r & CCCATTTAAATTTTAACCGGGGTTTTTGC \\
\hline Down-f & CCCGAGCTCCTGAAGCGGGAGATACAGAAAC \\
\hline Down-r & GAAGATCTCGCTTCAATCTCTCCCAAAGT \\
\hline \multicolumn{2}{|c|}{ For the identification of mutant strain (L. lactis N8-1) } \\
\hline Inner-f & AAATATGGAATTGAAGCATTTAA \\
\hline Inner-r & TTATTCTTTCGGTTTAGATGACT \\
\hline Exter-f & TGAATAAGAATTTGAACCCTTTA \\
\hline Exter-r & AGAAATTCTCTGATAAATTTTCTG \\
\hline Cat-f & TCAAATACAGCTTTTAGAACTGG \\
\hline Cat-r & TACAGTCGGCATTATCTCATATTA \\
\hline Ery-f & CTTGCTCATAAGTAACGGTAC \\
\hline Ery-r & CGATACCGTTTACGAAATTGG \\
\hline \multicolumn{2}{|c|}{ For the RT-qPCR } \\
\hline Q-tufA-f & GACCTCTTGAGCGAATACGACT \\
\hline Q-tufA-r & TTCTTCAACTTTAGCAACCCATT \\
\hline Q-rpsN-f & CCTGCAAAATTCTCAACACAAGC \\
\hline Q-rpsN-r & GCGAAGACAGATACGGCAAAGT \\
\hline Q-rplR-f & TGGTACTAAAACTGAACAAGCCG \\
\hline Q-rplR-r & TGCAACACGTCCGTGATAGAGGT \\
\hline$Q-\csc 2 B-f$ & ACAGGAGGAGCACTTTCAATCG \\
\hline Q-csc2B-r & GGTCCATCCATCCCAGGTT \\
\hline$Q-\csc 2 C-f$ & GCCAGTTTACAGGCACAGGTC \\
\hline$Q-\csc 2 C-r$ & GGATTAGCGTCATTCGTAGCATT \\
\hline Q-pi339-f & TAGTCGCAGCAGGAATCTTTG \\
\hline Q-pi339-r & TATCTTGATTGATTTGGTCTTTC \\
\hline Q-pp423-f & CGCAATAAGAAGAATGCCAAGC \\
\hline Q-pp423-r & GATGCCCCAGCGATCAATA \\
\hline Q-butA-f & ATTATCAACGCAACCTCACAAGC \\
\hline Q-butA-r & TCCCCATTCATCATCTTTACCAG \\
\hline Q-butB-f & CCGTCAGCAGAACATCCTAATC \\
\hline Q-butB-r & TCAGCCAATCCTCCACCAT \\
\hline Q-arcA-f & AAGCGGGTTACCGTCCAG \\
\hline Q-arcA-r & TTGGTAATGGGTTGAGGTAGAAA \\
\hline Q-arcB-f & GCTCCAGATTCACTTCATCCTAC \\
\hline Q-arcB-r & TCTTCCCAGTTAGATTCTCCCAT \\
\hline Q-galM-f & AATTGTTCGTGGTGATATCGTTG \\
\hline Q-galM-r & ATCACAATACTTGGTTGGTCGGT \\
\hline Q-galK-f & TCCTATTGGACTGTAACACTCTA \\
\hline Q-galK-r & TTCATCCCCAATCAAATCAGTAT \\
\hline Q-lacZ-f & CGGTCCGCTGCTCTCATTATCCT \\
\hline Q-lacZ-r & AGTCATTCCGTGCGTTTCG \\
\hline
\end{tabular}

(Takara) and the L. lactis N8 chromosome was used as template. Then, the fragments were ligated into the XhoI-SwaI and SacI-BglII restriction sites of pNZ5319. The recombinant plasmid pNZ5319-up-down obtained was transformed into E. coli $\mathrm{DH} 5 \alpha$ cells strain by $\mathrm{CaCl}_{2}$ method [52]. After verifying the accuracy of cloning (Additional file 1: Fig. S5), pNZ5319-up-down was isolated and electroporated into L. lactis N8 competent cells to generate mutant $L$. lactis N8-1-cat. After the deletion of the PRF, cat gene in the mutant was retrieved by introducing the plasmid pNZTS-Cre into L. lactis N8-1-cat strain. The final mutant was named as L. lactis N8-1 and used for further analysis.

\section{Genome resequencing}

Isolation of genomic DNA was carried out using SDS method. Total DNA obtained was subjected to quality control by agarose gel electrophoresis and quantified by Qubit (Thermo). The genome of L. lactis N8-1 was sequenced with MPS (massively parallel sequencing) Illumina technology (Illumina, San Diego, USA). The DNA library was constructed: a paired-end library with an insert size of $350 \mathrm{bp}$. The 350-bp library was sequenced using an Illumina PE150 strategy. Library construction and sequencing were performed at the Beijing Novogene Bioinformatics Technology Co., Ltd. Quality control of paired-end reads were performed using in-house program.

\section{Data processing}

The original figure data obtained by high-throughput sequencing platform of Illumina PE150 (Illumina) were transformed into raw sequenced reads by CASAVA base calling software (version 1.8.2; Illumina, Inc. USA), and stored in FASTQ format, containing sequencing information and the corresponding sequencing quality information of the reads. The sequenced data were filtered, and the sequence of adapter and low-quality data were removed, resulting in the clean data used for subsequent analysis.

\section{Reads mapping}

The reads comparison is the basis of the resequencing analysis. The variation information of the sample and the reference is obtained by aligning the sample reads with the designated reference sequence (L. lactis N8 genome). Mapping the reads to the reference sequence using BWA software (version 0.7.17; http://bio-bwa.sourceforge.net), counting the coverage of the reference sequence to the reads and make explanations of the alignment results using the SAMTOOLS software (version 1.11; http:// www.htslib.org).

\section{SV (structural variation) analysis}

SV refers to the insertion, deletion, inversion and translocation of the large segments in the genome level. The insertion, deletion, inversion, intra-chromosomal translocation, and inter-chromosomal translocation between 
the reference and the sample are found by Integrative Genomics Viewer software (version 2.6.3; https://igv. org). The variation map of the whole genome was created by Circos (version 0.6; http://circos.ca/software) to show reads coverage and the distribution of insertion and deletion information.

\section{Phenotype microarray analysis of the lactococcal strains (BIOLOG)}

Phenotype microarray system (Biolog, California, USA) was used to determine the metabolism of wild-type and mutant strains with GP2 MicroPlate ${ }^{\mathrm{TM}}$ [4]. Sample preparation and assays were conducted following the manufacturer's instructions. Briefly, a sterilized cotton swab was used to collect lactococcal cells from the surface of the solid medium and the cells were suspended in the inoculation (0.40\% sodium chloride, $0.03 \%$ Pluronic F-68, and $0.02 \%$ Gellan Gum) (Biolog). The cell density of different strains was equalized, and $150 \mu \mathrm{L}$ of the samples were pipetted into GP2 plate with various substrates. The plates were sealed with a cover and incubated in the OmniLog $^{\circledR}$ instrument (Biolog) at $30{ }^{\circ} \mathrm{C}$ for $24 \mathrm{~h}$. The data were recorded automatically by the machine every $30 \mathrm{~min}$ (15 s of shaking before recording), and analyzed using OL-OM 3.0 software (Biolog).

\section{Assessment of growth profiles}

For growth profile experiments, L. lactis strains were cultured at $30{ }^{\circ} \mathrm{C}$ for $6 \mathrm{~h}$ in static (non-aerated) condition to $\log$ phase, harvested by centrifugation $(5000 \times g$, $3 \mathrm{~min}$ ), and washed twice with PBS (phosphate buffered saline, $\mathrm{pH}$ 7.4). After washing, the cells were resuspended (adjusted to the same initial cell concentration) in GM17 medium as seed. For the determination of growth curves at different temperatures, we transferred $200 \mu \mathrm{L}$ of each sample to a Bioscreen honeycomb plate (100 wells). The growth profiles were monitored by measuring OD600 for $18 \mathrm{~h}$ at different temperatures $\left(30^{\circ} \mathrm{C}, 37^{\circ} \mathrm{C}, 39^{\circ} \mathrm{C}\right)$ by using the Bioscreen $C^{\mathrm{TM}}$ system (Lab-systems, Helsinki, Finland) [54]. For the determination of growth curves at different nisin concentrations, standard nisin was added at various concentrations $(4000,5000,6000,6500,7000$, and $7500 \mathrm{IU} / \mathrm{mL}$, respectively) to GM17 medium to obtain six groups. Then, the seeds were inoculated at a concentration of $1 \%$, and $200 \mu \mathrm{L}$ of each sample were transferred to a Bioscreen honeycomb plate (100 wells). The growth profiles were monitored by measuring OD600 for $48 \mathrm{~h}$ at $30{ }^{\circ} \mathrm{C}$ by using the Bioscreen $\mathrm{C}^{\mathrm{TM}}$ system. For the determination of growth curves at different lactic acid concentrations, lactic acid $[80 \%(\mathrm{v} / \mathrm{v})]$ was added at various concentrations $[0.24 \%(\mathrm{v} / \mathrm{v}), 0.32 \%(\mathrm{v} / \mathrm{v})$, and, $0.40 \%(\mathrm{v} / \mathrm{v})$, respectively)] to GM17 medium to obtain three groups. Then, the seeds were inoculated at a concentration of
$1 \%$ and $200 \mu \mathrm{L}$ of each sample were transferred to a Bioscreen honeycomb plate (100 wells). The growth profiles were monitored by measuring OD600 for $18 \mathrm{~h}$ at $30{ }^{\circ} \mathrm{C}$ by using the Bioscreen $\mathrm{C}^{\mathrm{TM}}$ system. The OD600 was measured at 15-min intervals, and static culture was gently agitated for $10 \mathrm{~s}$ before each measurement.

\section{Assessment of nisin immunity}

The nisin immunity of wild-type and mutant strains was determined by the 96-well plate gradient dilution method [25] with minor modifications. Briefly, the wild-type and mutant strains were grown for $6 \mathrm{~h}$ in antibiotic-free GM17 medium, and then washed twice with PBS. After washing, the cells were resuspended in GM17 medium and adjusted to the same cell concentration, and then diluted to a ratio of 1:1000 as seed solution. Nisin was added with a gradient concentration of 2000-8000 IU/ $\mathrm{mL}$ at intervals of $500 \mathrm{IU} / \mathrm{mL}$. Subsequently, $2 \mu \mathrm{L}$ of seed solution were added into $198 \mu \mathrm{L}$ of gradient nisin medium, and the mixtures were incubated at $30{ }^{\circ} \mathrm{C}$ for $20 \mathrm{~h}$ in 96-well plate. The cell concentration data were collected by microplate reader (Synergy 2, BioTek Instruments, Inc.) at a wavelength of $600 \mathrm{~nm}$. The nisin immunity of the strains was determined as the minimum nisin concentration needed to ensure that the turbidity did not change to $>10 \%$ at $600 \mathrm{~nm}$. The next lower nisin concentration was determined as the nisin immunity level of the tested strain.

\section{Assessment of lysozyme and lactic acid tolerances}

To determine lysozyme and lactic acid tolerances, the lactococcal cells were cultured at $30{ }^{\circ} \mathrm{C}$ for $6 \mathrm{~h}$ in static (non-aerated) condition to log phase and harvested by centrifugation $(5000 \times g, 3 \mathrm{~min})$, washed twice with PBS, and resuspended in equal volume of GM17 medium. Lysozyme and lactic acid were added to the cell suspension at a final concentration of $10 \mathrm{mg} / \mathrm{mL}$ and $1.5 \%(\mathrm{v} / \mathrm{v})$, respectively. Cell viability was determined at various time points $(30,60,90$, and $120 \mathrm{~min})$ by colony counting. A total of $5 \mu \mathrm{L}$ of serially diluted cell suspension were spotted on GM17 plates and cultured at $30{ }^{\circ} \mathrm{C}$ for $20 \mathrm{~h}$, and then the plates were photographed. For survival rate experiments, colonies on plates containing 20-200 CFU were counted [44].

\section{Assessment of nisin yield}

Nisin yield was determined by the agar well diffusion method [55] with minor modifications. Briefly, the broth of the tested strains after fermentation was boiled for $10 \mathrm{~min}$ and cells were removed by centrifugation at $8000 \mathrm{rpm}$ for $3 \mathrm{~min}$. Then, the supernatant was appropriately diluted with $0.02 \mathrm{M} \mathrm{HCl}$. M. luteus $\left(10^{7} \mathrm{CFU} / \mathrm{mL}\right)$ was used as indicator and inoculated at a concentration 
of $1 \%(\mathrm{v} / \mathrm{v})$ into $30-\mathrm{mL}$ melted/cooled LB agar. To enhance nisin diffusion, $1.5 \%(\mathrm{v} / \mathrm{v})$ Tween 80 (JiangTian, Tianjin, China) was added to the medium and mixed well. Then, the medium was quickly poured into sterile plates. After solidification and pre-cultivation, a 7-mm-diameter sterile cork borer (MRS Scientific Ltd, Wickford, UK) was used to generate agar well for loading samples. Standard nisin solutions (concentrations of 20, 40, 80, 100, 200, and $400 \mathrm{IU} / \mathrm{mL}$ ) were prepared using nisin powder. Subsequently, the standard nisin solutions and sample solutions were respectively loaded into the wells $(80 \mu \mathrm{L}$ per well), and the plates were incubated at $37^{\circ} \mathrm{C}$ for $24 \mathrm{~h}$. The diameter of inhibition zone was measured by calipers. A regression equation was derived from the nisin standard data.

\section{SEM}

The lactococcal cells were cultured at $30{ }^{\circ} \mathrm{C}$ for $6 \mathrm{~h}$ to exponential phase, harvested at $8000 \mathrm{rpm}$ for $2 \mathrm{~min}$, and washed twice with PBS. The cells were resuspended in equal volume of GM17 medium (supplemented with lysozyme to a final concentration of $17.5 \mathrm{mg} / \mathrm{mL}$ ) and incubated for $1 \mathrm{~h}$ and $2 \mathrm{~h}$. The bacterial cells without lysozyme treatment were set as controls. After incubation, the cells were washed with PBS and fixed overnight in $2.5 \%$ glutaraldehyde (Sigma) at $4{ }^{\circ} \mathrm{C}$. Then, the cells were washed with PBS and dehydrated using gradient ethanol (50-100\%, 15 min for each gradient). After dehydration, ethanol was replaced with tertiary butyl alcohol (Sigma). Subsequently, the samples were added onto the plate and prepared for SEM (QUANTA 200) observation [56].

\section{Flasks fermentation and fed-batch fermentation}

After overnight cultivation, L. lactis N8 and L. lactis N8-1 were inoculated in GM17 medium for $6 \mathrm{~h}$ as seed cultures. To perform the flask fermentation experiments, 250-mL Erlenmeyer flasks containing $100 \mathrm{~mL}$ of GM17 fermentation medium were used. A total of $1 \mathrm{~mL}$ of the seed cultures was inoculated into static flasks and incubated for $16 \mathrm{~h}$ at $30^{\circ} \mathrm{C}$. Samples were collected every $2 \mathrm{~h}$ for the analysis of cell density, fermentation broth $\mathrm{pH}$, and nisin production. Fed-batch fermentation experiments were conducted at $30{ }^{\circ} \mathrm{C}$ for $16 \mathrm{~h}$. Initially, the $\mathrm{pH}$ of the three groups of fermentation medium was adjusted to $\mathrm{pH} 6.0,5.5$, and 5.0 with $80 \%(\mathrm{v} / \mathrm{v})$ lactic acid, respectively. Then, three groups of media were inoculated with $1 \%$ of seed culture. The $\mathrm{pH}$ of the three fermentation broths was controlled at $6.0,5.5$, and 5.0 by adding $10 \mathrm{M}$ $\mathrm{NaOH}$, respectively. The fermentation broths were sampled every $2 \mathrm{~h}$ for the analysis of cell density, fermentation broth $\mathrm{pH}$, and nisin production.

\section{TMT quantitative proteomics and analysis}

TMT-labeled quantitative proteomics technology was applied to reveal changes in protein synthesis of L. lactis N8-1 and perform functional analysis of differentially synthetized proteins. The TMT quantitative proteomics of L. lactis N8 and L. lactis N8-1 were performed by Shanghai Majorbio Bio-pharm Technology Co., Ltd. (Shanghai, China) as following:

\section{Total protein extraction}

The L. lactis samples were suspended with protein lysis buffer (1\% SDS, 200 mM DTT, 50 mM Tris-HCl, pH 8.8) which included appropriate protease inhibitor to inhibit protease activity, and treated for three times by high throughput tissue crusher Wonbio-96c (WanBo biotechnology co., Ltd, Shanghai, China) for $40 \mathrm{~s}$. Then, the mixture was incubated on ice for $30 \mathrm{~min}$ during which the samples were vortexed 5-10 s every $5 \mathrm{~min}$. Samples were incubated at $100{ }^{\circ} \mathrm{C}$ for $10 \mathrm{~min}$, then transferred on ice for $30 \mathrm{~min}$. After that, samples were centrifuged at $12,000 \times g$ for $20 \mathrm{~min}$ at $4{ }^{\circ} \mathrm{C}$, and supernatants were collected. Five volumes of pre-cooled acetone (Sigma) were added and proteins were precipitated at $-20{ }^{\circ} \mathrm{C}$ overnight. The second day, the solution was centrifuged at $12,000 \times g$ for $20 \mathrm{~min}$ at $4{ }^{\circ} \mathrm{C}$. The supernatant was discarded and the precipitation was washed twice with $90 \%$ pre-cooled acetone. Lysis buffer (1\% SDS, $8 \mathrm{M}$ urea, cocktail) was used to resuspend the precipitation, then samples were centrifugated at $12,000 \times g$ for $20 \mathrm{~min}$ at $4{ }^{\circ} \mathrm{C}$. The protein concentration in the supernatant was determined by bicinchoninic acid (BCA) method using BCA Protein Assay Kit (Beyotime biotechnology, Shanghai, China).

\section{Protein digestion and TMT labeling}

One hundred microgram of proteins were resuspended with tetraethylammonium bromide (Haihang Industry, Jinan, China) at a final concentration of $100 \mathrm{mM}$. The mixture was reduced with tris (2-carboxyethyl) phosphine (Sigma) at a final concentration of $10 \mathrm{mM}$ at $37{ }^{\circ} \mathrm{C}$ for $60 \mathrm{~min}$, and alkylated with iodoacetamide (Sigma) at a final concentration of $40 \mathrm{mM}$ at room temperature for $40 \mathrm{~min}$ in darkness. Six fold volumes of cold acetone were added to precipitate protein at $-20{ }^{\circ} \mathrm{C}$ for $4 \mathrm{~h}$. After centrifugation at $10,000 \times g$ at $4{ }^{\circ} \mathrm{C}$ for $20 \mathrm{~min}$, the pellet was resuspended with $100 \mu \mathrm{L} 50 \mathrm{mM}$ riethylammonium bicarbonate buffer (Sigma). Trypsin was added at 1:50 trypsin-to-protein mass ratio and incubated at $37{ }^{\circ} \mathrm{C}$ overnight. Trypsin-digested peptides were labeled with 10-plex TMT reagents (Thermo) according to the manufacturer's instructions. Briefly, one unit of TMT reagent were thawed and reconstituted in $50 \mu \mathrm{L}$ acetonitrile (Sigma). After tagging for $2 \mathrm{~h}$ at room temperature, 
hydroxylamine (Thermo) was added to react for $15 \mathrm{~min}$ at room temperature. Finally all samples were pooled, desalted and vacuum-dried.

\section{High pH RPLC separation and LC-MS/MS analysis}

The pooled samples were fractionated into fractions by ACQUITY Ultra Performance liquid chromatography (Waters, USA) with ACQUITY UPLC BEH C18 Column $(1.7 \mu \mathrm{m}, 2.1 \mathrm{~mm} \times 150 \mathrm{~mm}$, Waters, USA) to increase proteomic depth. Briefly, peptides were first separated with a gradient of elution (Phase B: $5 \mathrm{mM}$ ammonium hydroxide solution containing $80 \%$ acetonitrile, $\mathrm{pH} 10$ ) over $66 \mathrm{~min}$ at a flowrate of $200 \mu \mathrm{L} / \mathrm{min}$. Twenty fractions were collected from each sample, which were subsequently pooled, resulting in ten total fractions per sample. Then, trypsin-digested peptides were analyzed by online nano flow liquid chromatography tandem mass spectrometry performed on an EASY-nLC system (Thermo Fisher Scientific) connected to a Q Exactive quadrupole orbitrap mass spectrometer (Thermo) through a nanoelectrospray ion source. Briefly, the C18-reversed phase column $(75 \mu \mathrm{m} \times 25 \mathrm{~cm}$, Thermo Fisher Scientific) was equilibrated with solvent A (A: $2 \% \mathrm{ACN}$ with $0.1 \%$ formic acid) and solvent B (B: $80 \%$ ACN with $0.1 \%$ formic acid). The peptides were eluted using the following gradient: $0-1 \mathrm{~min}, 0-5 \% \mathrm{~B} ; 1-63 \mathrm{~min}, 5-23 \% \mathrm{~B} ; 63-88 \mathrm{~min}$, $23-48 \%$ B; 88-89 min, $48-100 \%$ B; and $89-95$ min, $100 \%$ B. The tryptic peptides were separated at a flow rate of $300 \mathrm{~nL} / \mathrm{min}$. The Q Exactive plus instrument was operated in the data-dependent acquisition mode (DDA) to automatically switch between full scan MS and MS/MS acquisition. The survey of full scan MS spectra (m/z 3501300) was acquired in the Orbitrap with 70,000 resolution. The automatic gain control (AGC) target at $1 \mathrm{e} 6$ and the maximum fill time was $50 \mathrm{~ms}$. Then the top 20 most intense precursor ions were selected into collision cell for fragmentation by higher-energy collision dissociation (HCD). The MS/MS resolution was set at 35,000 (m/z 100), the automatic gain control (AGC) target at 1e5, the maximum fill time at $100 \mathrm{~ms}$, and dynamic exclusion was $18 \mathrm{~s}$.

\section{Protein identification}

MS/MS spectra were searched using Protein Discoverer $^{\mathrm{TM}}$ Software 2.1 (Thermo Fisher Scientific) against Streptococcus lactis database and the decoy database as the following parameters. The highest score for a given peptide mass (best match to that predicted in the database) was used to identify parent proteins. The parameters for protein searching were set as follows: tryptic digestion with up to two missed cleavages, carbamidomethylation of cysteines and the TMT of N-terminus and lysine side chains of peptides as a fixed modification, and oxidation of methionines and protein $\mathrm{N}$-terminal acetylation as variable modifications. Peptide spectral matches were validated based on Q-values at a $1 \%$ false discovery rate (FDR). Only the proteins which has at least one unique peptide was used for protein identifications. Proteins that changed more than 1.5-fold (up or down regulated) with a $P$-value less than 0.05 between $L$. lactis N8-1 and L. lactis N8 were deemed significantly difference proteins. The Uniprot database (https://www.unipr ot.org/) and Pfam (http://pfam.xfam.org) were used for protein sequence search, alignment analysis, and protein domain prediction. The databases used for metabolic pathway search and analysis were iPath3.0 (https:// pathways.embl.de/) and KEGG (https://www.genome.jp/ kegg/). NCBI BLASTp (https://blast.ncbi.nlm.nih.gov/ Blast.cgi?PROGRAM=blastp\&PAGETYPE = BlastSearc h\&LINK_LOC=blasthome) was used for protein function domain prediction. Subcellular location database (https://abi-services.informatik.uni-tuebingen.de/yloc/ webloc.cgi) was used to predict the location where proteins appear in the cell.

\section{Quantitative real-time PCR}

Lactococcus lactis N8 and L. lactis N8-1 were cultured in GM17 medium for $6 \mathrm{~h}$ and appropriately diluted to achieve similar cell density. Then, the total RNA was extracted and reversed-transcribed into first-strand cDNA using RevertAid First Strand cDNA Synthesis Kit (Thermo Fisher Scientific). The gene transcription levels of $r p s N, r p l R, c s c 2 B, c s c 2 C$, pi339, pp423, butA, butB, $\operatorname{arcA}$, arcB, galM, galK and lac $Z$ were then assessed through RT-qPCR to confirm the proteomics data. The tufA gene was selected as housekeeping gene [57] and comparative $\mathrm{CT}\left(2^{-\Delta \Delta C \mathrm{~T}}\right)$ method was employed for data analysis. Transcription with more than two-fold change was regarded as statistically significantly different.

\section{Statistical analysis}

The experiments to determine the growth profiles of $L$. lactis under different treatments (nisin, temperature, and lactic acid) were performed in independent biological triplicates, and each sample was additionally collected in technical triplicates. The experiments to determine the survival rates of $L$. lactis under different treatments (lysozyme and lactic acid) were independently repeated at least three times. The data are shown as mean \pm standard deviation (SD). Assays to determine the nisin immunity of L. lactis in 96-well plate and nisin yield of different $L$. lactis strains under diverse treatments $(\mathrm{pH}$ $6.0,5.5,5.0$ ) were independently repeated at least three times. The difference between two groups was compared by the Student's $t$-test and values with $P<0.05$ were considered significant. RT-qPCR experiments were 
independently repeated at least three times, and the data are given as mean $\pm \mathrm{SD}$. Statistical analyses of the data were performed using Origin 85 software version 8.5.0 SRI (OriginLab Corporation, USA) and GraphPad Prism 5 software version 5.01 (GraphPad software, Inc.).

\section{Supplementary Information}

The online version contains supplementary material available at https://doi. org/10.1186/s12934-020-01487-x.

Additional file 1: Fig. S1. KEGG functional enrichment (L. lactis N8-1 vs L. lactis N8). a Upregulated proteins ( $>1.2$-fold change with $P<0.05$ ); b downregulated proteins ( $>1.2$-fold change with $P<0.05$ ). Fig. S2. Gene Ontology (GO) function annotations. a all proteins; $b$ upregulated proteins (>1.2-fold change with $P<0.05$ ); c downregulated proteins ( $>1.2$-fold change with $P<0.05)$. Fig. S3. Diagram of protein subcellular localization. Red bars indicate upregulated proteins ( $>1.2$-fold change with $P<0.05$ ), green bars indicate downregulated proteins ( $>1.2$-fold change with $P<0.05)$. Fig. S4. RT-qPCR analysis of genes with higher and lower expression level. rps $N$, rplR: ribosomal protein; $\csc 2 B, \csc 2 C$ : cell surface protein; pi339, pp423: bacteriophage protein; butA, butB: butanoate metabolism protein; $\operatorname{arcA}$, arcB: arginine biosynthesis protein; galM, galK: galactose metabolism protein: lacZ; beta-galactosidase. Fig. S5. PCR verification of the knockout vector construction. Table S1. Gene content of deleted PRF. Table S2. Substrate consumption ratio. Table S3. Nisin-immunity of engineered strains. Table S4. Upregulated proteins ( $>1$.2-fold change with $P<0.05)$. Table S5. Downregulated proteins $(>1.2$-fold change with $P<0.05)$.

\section{Abbreviations}

LAB: Lactic acid bacteria; gTME: Global transcription machinery engineering; PRF: Prophage-related fragment; MS: Mass spectrometry; 2-DE: Two-dimensional gel electrophoresis; TMT: Tandem mass tags; HSP: Heat shock protein; CSP: Cold shock protein; BCA: Bicinchoninic acid; SD: Standard deviation.

\section{Acknowledgements}

We thank the free online platform of Majorbio Cloud Platform (www.majorbio. com) for data analysis.

\section{Authors' contributions}

WQ designed the study, analyzed the primary data and drafted the manuscript. WQ, YQ, FL, YZ, and RL carried out the experiments. ZW, HX, PS, and MQ supervised the whole research work and revised the manuscript. All authors read and approved the final manuscript.

\section{Funding}

This work was financially supported by the National Natural Science Foundation of China (31770102). Wanjin Qiao is supported by the Chinese Scholarship Council (CSC).

\section{Availability of data and materials}

All data generated or analyzed during this study are included in this published article and its additional file.

\section{Ethics approval and consent to participate \\ Not applicable.}

\section{Consent for publication}

Not applicable.

\section{Competing interests}

The authors declare that they have no competing interests.

\section{Author details}

${ }^{1}$ Key Laboratory of Molecular Microbiology and Technology, Ministry of Education, College of Life Sciences, Nankai University, No.94 Weijin Road,
Nankai District, Tianjin 300071, China. ${ }^{2}$ Department of Microbiology, Faculty of Agriculture and Forestry, University of Helsinki, Helsinki, Finland. ${ }^{3}$ State Key Laboratory of Medicinal Chemical Biology \& Tianjin Key Laboratory of Protein Sciences, College of Life Sciences, Nankai University, Tianjin, China.

Received: 11 August 2020 Accepted: 28 November 2020

Published online: 09 December 2020

\section{References}

1. Jensen PR, Liu J, Chan SHJ, Chen J, Solem C. Systems biology-a guide for understanding and developing improved strains of lactic acid bacteria. Front Microbiol. 2019;10:876.

2. Song AA-L, In LL, Lim SHE, Rahim RA. A review on Lactococcus lactis: from food to factory. Microb Cell Fact. 2017;16:55.

3. Broadbent JR, Larsen RL, Deibel V, Steele JL. Physiological and transcriptional response of Lactobacillus casei ATCC 334 to acid stress. J Bacteriol. 2010;192:2445-58.

4. Zhu D, Fu Y, Liu F, Xu H, Saris PEJ, Qiao M. Enhanced heterologous protein productivity by genome reduction in Lactococcus lactis NZ9000. Microb Cell Fact. 2017;16:1.

5. Gao X, Jiang L, Zhu L, Xu Q, Xu X, Huang H. Tailoring of global transcription sigma $D$ factor by random mutagenesis to improve Escherichia coli tolerance towards low-pHs. J Biotechnol. 2016;224:55-63.

6. Alper H, Moxley J, Nevoigt E, Fink GR, Stephanopoulos G. Engineering yeast transcription machinery for improved ethanol tolerance and production. Science. 2006;314:1565-8.

7. Gao X, Yang X, Li J, Zhang Y, Chen P, Lin Z. Engineered global regulator $\mathrm{H}-\mathrm{NS}$ improves the acid tolerance of Escherichia coli. Microb Cell Fact. 2018;17:118.

8. Li Y, Xu X, Qu R, Zhang G, Rajoka MSR, Shao D, Jiang C, Shi J. Heterologous expression of Oenococcus oeni sHSP20 confers temperature stress tolerance in Escherichia coli. Cell Stress Chaperones. 2018;23:653-62.

9. Zhang M, Zhang K, Mehmood MA, Zhao ZK, Bai F, Zhao X. Deletion of acetate transporter gene ADY2 improved tolerance of Saccharomyces cerevisiae against multiple stresses and enhanced ethanol production in the presence of acetic acid. Bioresour Technol. 2017;245:1461-8.

10. Dong X, Tian B, Dai S, Li T, Guo L, Tan Z, Jiao Z, Jin Q, Wang Y, Hua $Y$. Expression of Pprl from Deinococcus radiodurans improves lactic acid production and stress tolerance in Lactococcus lactis. PLOS ONE. 2015;10:e0142918.

11. Desmond C, Fitzgerald G, Stanton C, Ross R. Improved stress tolerance of GroESL-overproducing Lactococcus lactis and probiotic Lactobacillus paracasei NFBC 338. Appl Environ Microbiol. 2004;70:5929-36.

12. Wang Y, Li Y, Pei X, Yu L, Feng Y. Genome-shuffling improved acid tolerance and L-lactic acid volumetric productivity in Lactobacillus rhamnosus. J Biotechnol. 2007;129:510-5.

13. Qi J, Caiyin Q, Wu H, Tian K, Wang B, Li Y, Qiao J. The novel sRNA s015 improves nisin yield by increasing acid tolerance of Lactococcus lactis F44. Appl Microbiol Biotechnol. 2017;101:6483-93.

14. Li Y, Kan Z, You Y, Gao X, Wang Z, Fu R. Exogenous transglutaminase improves multiple-stress tolerance in Lactococcus lactis and other lactic acid bacteria with glutamine and lysine in the cell wall. Biotechnol Lett. 2015;37:2467-74

15. López-González MJ, Campelo AB, Picon A, Rodríguez A, Martínez B. Resistance to bacteriocin Lcn972 improves oxygen tolerance of Lactococcus lactis IPLA947 without compromising its performance as a dairy starter. BMC Microbiol. 2018;18:76.

16. Kimoto $\mathrm{H}$, Ohmomo S, Okamoto T. Enhancement of bile tolerance in lactococci by Tween 80. J Appl Microbiol. 2002;92:41-6.

17. Liang P, Zhang Y, Xu B, Zhao Y, Liu X, Gao W, Ma T, Yang C, Wang S, Liu R. Deletion of genomic islands in the Pseudomonas putida KT2440 genome can create an optimal chassis for synthetic biology applications. Microb Cell Fact. 2020;19:1-12.

18. Martínez-García E, Nikel PI, Aparicio T, de Lorenzo V. Pseudomonas 2.0: genetic upgrading of P. putida KT2440 as an enhanced host for heterologous gene expression. Microb Cell Fact. 2014;13:159.

19. Zhang $H$, Zhang $C$, Wang $H$, Yan $Y X$, Sun J. A novel prophage lysin Ply5218 with extended lytic activity and stability against Streptococcus suis infection. FEMS Microbiol Lett. 2016;363:fnw186. 
20. Wu H, Zhao Y, Du Y, Miao S, Liu J, Li Y, Caiyin Q, Qiao J. Quantitative proteomics of Lactococcus lactis F44 under cross-stress of low pH and lactate. J Dairy Sci. 2018;101:6872-84.

21. Kramer NE, Hasper HE, van den Bogaard PT, Morath S, de Kruijff B, Hartung T, Smid EJ, Breukink E, Kok J, Kuipers OP. Increased D-alanylation of lipoteichoic acid and a thickened septum are main determinants in the nisin resistance mechanism of Lactococcus lactis. Microbiology. 2008; 154:1755-62.

22. Kelleher P, Mahony J, Schweinlin $\mathrm{K}$, Neve H, Franz CM, van Sinderen D. Assessing the functionality and genetic diversity of lactococcal prophages. Int J Food Microbiol. 2018;272:29-40.

23. Aucouturier A, Chain F, Langella P, Bidnenko E. Characterization of a prophage-free derivative strain of Lactococcuslactis ssp. lactis IL1403 reveals the importance of prophages for phenotypic plasticity of the host. Front Microbiol. 2018;9:2032.

24. Kim W, Hall R, Dunn N. Improving nisin production by increasing nisin immunity/resistance genes in the producer organism Lactococcus lactis. Appl Microbiol Biotechnol. 1998;50:429-33.

25. Xuanyuan Z, Wu Z, Li R, Jiang D, Su J, Xu H, Bai Y, Zhang X, Saris PEJ, Qiao $M$. Loss of IrpT function in Lactococcus lactis subsp. lactis N8 results in increased nisin resistance. Curr Microbiol. 2010;61:329-34.

26. Sun Z, Zhong J, Liang X, Liu J, Chen X, Huan L. Novel mechanism for nisin resistance via proteolytic degradation of nisin by the nisin resistance protein NSR. Antimicrob Agents Chemother. 2009;53:1964-73.

27. Qiao M, Immonen T, Koponen O, Saris PE. The cellular location and effect on nisin immunity of the Nisl protein from Lactococcuslactis N8 expressed in Escherichiacoli and L. lactis. FEMS Microbiol Lett. 1995;131:75-80.

28. Wilkins MR, Sanchez J-C, Gooley AA, Appel RD, Humphery-Smith I, Hochstrasser DF, Williams KL. Progress with proteome projects: why all proteins expressed by a genome should be identified and how to do it. Biotechnol Genet Eng Rev. 1996;13:19-50.

29. Ong S-E, Mann M. Mass spectrometry-based proteomics turns quantitative. Nat Chem Biol. 2005;1:252-62.

30. Aebersold R, Mann M. Mass spectrometry-based proteomics. Nature. 2003:422:198-207.

31. Lambert JM, Bongers RS, Kleerebezem M. Cre-lox-based system for multiple gene deletions and selectable-marker removal in Lactobacillus plantarum. Appl Environ Microbiol. 2007;73:1126-35.

32. Zhou Y, Liang Y, Lynch KH, Dennis JJ, Wishart DS. PHAST: a fast phage search tool. Nucleic Acids Res. 2011;39:W347-52.

33. Sanders JW, Venema G, Kok J. Environmental stress responses in Lactococcus lactis. FEMS Microbiol Rev. 1999;23:483-501.

34. Papadimitriou K, Alegría Á, Bron PA, de Angelis M, Gobbetti M, Kleerebezem M, Lemos JA, Linares DM, Ross P, Stanton C, et al. Stress physiology of lactic acid bacteria. Microbiol Mol Biol Rev. 2016;80:837-90.

35. Jiang W, Hou Y, Inouye M. CspA, the major cold-shock protein of Escherichia coli, is an RNA chaperone. J Biol Chem. 1997;272:196-202.

36. Wouters JA, Sanders J-W, Kok J, De Vos WM, Kuipers OP, Abee T. Clustered organization and transcriptional analysis of a family of five csp genes of Lactococcus lactis MG 1363. Microbiology. 1998;144:2885-93.

37. Nannen NL, Hutkins RW. Proton-translocating adenosine triphosphatase activity in lactic acid bacterial. J Dairy Sci. 1991;74:747-51.

38. Marquis RE, Bender GR, Murray DR, Wong A. Arginine deiminase system and bacterial adaptation to acid environments. Appl Environ Microbiol. 1987:53:198-200.

39. Fernándes L, Steele JL. Glutathione content of lactic acid bacteria. J Dairy Sci. 1993;76:1233-42.

40. Fahey R, Brown W, Adams W, Worsham M. Occurrence of glutathione in bacteria. J Bacteriol. 1978;133:1126-9.

41. Duwat P, Sourice S, Ehrlich S, Gruss A. recA gene involvement in oxidative and thermal stress in Lactococcus lactis. Dev Biol Stand. 1995;85:455-67.

42. Sugimoto S, Higashi C, Matsumoto S, Sonomoto K. Improvement of multiple-stress tolerance and lactic acid production in Lactococcus lactis NZ9000 under conditions of thermal stress by heterologous expression of Escherichia coli dnaK. Appl Environ Microbiol. 2010;76:4277-85.

43. Hagi T, Kobayashi M, Kawamoto S, Shima J, Nomura M. Expression of novel carotenoid biosynthesis genes from Enterococcus gilvus improves the multistress tolerance of Lactococcus lactis. J Appl Microbiol. 2013;114:1763-71.

44. Zhu Z, Yang J, Yang P, Wu Z, Zhang J, Du G. Enhanced acid-stress tolerance in Lactococcus lactis NZ9000 by overexpression of ABC transporters. Microb Cell Fact. 2019:18:136.

45. Draper LA, Cotter PD, Hill C, Ross RP. Lantibiotic resistance. Microbiol Mol Biol Rev. 2015;79:171-91.

46. Kramer NE, van Hijum SA, Knol J, Kok J, Kuipers OP. Transcriptome analysis reveals mechanisms by which Lactococcus lactis acquires nisin resistance. Antimicrob Agents Chemother. 2006;50:1753-61.

47. Sala RF, Morgan PM, Tanner ME. Enzymatic formation and release of a stable glycal intermediate: the mechanism of the reaction catalyzed by UDPN-acetylglucosamine 2-epimerase. J Am Chem Soc. 1996;1 18:3033-4.

48. Siezen R, Boekhorst J, Muscariello L, Molenaar D, Renckens B, Kleerebezem M. Lactobacillus plantarum gene clusters encoding putative cell-surface protein complexes for carbohydrate utilization are conserved in specific gram-positive bacteria. BMC Genomics. 2006;7:126.

49. Brinster S, Furlan S, Serror P. C-terminal WxL domain mediates cell wall binding in Enterococcus faecalis and other gram-positive bacteria. J Bacteriol. 2007:189:1244-53.

50. Pieterse B, Leer RJ, Schuren FH, van der Werf MJ. Unravelling the multiple effects of lactic acid stress on Lactobacillus plantarum by transcription profiling. Microbiology. 2005;151:3881-94.

51. Egan AJ, Cleverley RM, Peters K, Lewis RJ, Vollmer W. Regulation of bacterial cell wall growth. FEBS J. 2017;284:851-67.

52. Tang X, Nakata Y, Li H-O, Zhang M, Gao H, Fujita A, Sakatsume O, Ohta T, Yokoyama K. The optimization of preparations of competent cells for transformation of Escherichia coli. Nucleic Acids Res. 1994;22:2857.

53. Zhu D, Zhao K, Xu H, Zhang X, Bai Y, Saris PE, Qiao M. Construction of thy A deficient Lactococcus lactis using the Cre-loxP recombination system. Ann Microbiol. 2015:65:1659-65.

54. Wan X, Li R, Saris PE, Takala TM. Genetic characterisation and heterologous expression of leucocin C, a class lla bacteriocin from Leuconostoc carnosum 4010. Appl Microbiol Biotechnol. 2013;97:3509-18.

55. Zhang J, Caiyin Q, Feng W, Zhao X, Qiao B, Zhao G, Qiao J. Enhance nisin yield via improving acid-tolerant capability of Lactococcus lactis F44. Sci Rep. 2016;6:1-12.

56. Fu Y, Mu D, Qiao W, Zhu D, Wang X, Liu F, Xu H, Saris P, Kuipers OP, Qiao M. Co-expression of nisin Z and Leucocin C as a basis for effective protection against Listeria monocytogenes in pasteurized milk. Front Microbiol. 2018;9:547.

57. Castro R, Neves AR, Fonseca LL, Pool WA, Kok J, Kuipers OP, Santos H. Characterization of the individual glucose uptake systems of Lactococcus lactis: mannose-PTS, cellobiose-PTS and the novel GlcU permease. Mol Microbiol. 2009;71:795-806.

58. Woodcock DM, Crowther PJ, Doherty J, Jefferson S, DeCruz E, NoyerWeidner M, Smith SS, Michael MZ, Graham MW. Quantitative evaluation of Escherichia coli host strains for tolerance to cytosine methylation in plasmid and phage recombinants. Nucleic Acids Res. 1989;17:3469-78.

59. Qiao M, Ye S, Koponen O, Ra R, Usabiaga M, Immonen T, Saris P. Regulation of the nisin operons in Lactococcus lactis N8. J Appl Bacteriol. 1996;80:626-34.

60. Kuipers OP, de Ruyter PG, Kleerebezem M, de Vos WM. Quorum sensing-controlled gene expression in lactic acid bacteria. J Biotechnol. 1998;64:15-21.

61. Zhu D, Liu F, Xu H, Bai Y, Zhang X, Saris PEJ, Qiao M. Isolation of strong constitutive promoters from Lactococcuslactis subsp. lactis N8. FEMS Microbiol Lett. 2015;362:fnv107.

62. Şimşek Ö, Çon AH, Akkoç N, Saris PEJ, Akçelik M. Influence of growth conditions on the nisin production of bioengineered Lactococcus lactis strains. J Ind Microbiol Biotechnol. 2009;36:481.

\section{Publisher's Note}

Springer Nature remains neutral with regard to jurisdictional claims in published maps and institutional affiliations. 